\title{
REVIEW ON ENERGY EFFICIENT OPPORTUNISTIC ROUTING PROTOCOL FOR UNDERWATER WIRELESS SENSOR NETWORKS
}

\author{
Nasarudin Ismail ${ }^{1,2, *}$, M. M. Mohamad ${ }^{2}$ \\ ${ }^{1}$ Faculty of Computer Science and Information Technology, \\ Universiti Tun Hussein Onn Malaysia \\ ${ }^{2}$ Faculty of Computing, \\ Universiti Teknologi Malaysia \\ [e-mail: nasar@uthm.edu.my] ${ }^{1,2}$ \\ [e-mail: murtadha@utm.my] ${ }^{2}$ \\ *Corresponding author: Nasarudin Ismail
}

Received August 20, 2017; revised November 23, 2017; revised February 3 2018; accepted February 28, 2018; published July 31, 2018

\begin{abstract}
Currently, the Underwater Sensor Networks (UWSNs) is mainly an interesting area due to its ability to provide a technology to gather many valuable data from underwater environment such as tsunami monitoring sensor, military tactical application, environmental monitoring and many more. However, UWSNs is suffering from limited energy, high packet loss and the use of acoustic communication. In UWSNs most of the energy consumption is used during the forwarding of packet data from the source to the destination. Therefore, many researchers are eager to design energy efficient routing protocol to minimize energy consumption in UWSNs. As the opportunistic routing (OR) is the most promising method to be used in UWSNs, this paper focuses on the existing proposed energy efficient OR protocol in UWSNs. This paper reviews the existing proposed energy efficient OR protocol, classifying them into 3 categories namely sender-side-based, receiver-side-based and hybrid. Furthermore each of the protocols is reviewed in detail, and its advantages and disadvantages are discussed. Finally, we discuss potential future work research directions in UWSNs, especially for energy efficient OR protocol design.
\end{abstract}

Keywords: Energy Efficient, Opportunistic Routing protocol, Traffic Reduction approach, Underwater Wireless Sensor Networks 


\section{Introduction}

Although the Earth's surface is covered by water over 70\% compared to the land, human knowledge about the underwater environment is still too shallow as compared to the land. Due to technological advances in wireless sensor networks (WSNs) nowadays, the exploration of knowledge about the land and its structure is able to grow successfully. This remarkably encourages researcher to venture with the same technology for use in the underwater environment which is called Underwater Wireless Sensors Networks (UWSNs)[1]. Due to the reasons of harsh underwater environment, vast area and high water pressure, employing the UWSNs is the way for un-manned exploration in that environment[2].

UWSNs is usually made up of autonomous vehicles and individual sensor nodes that implement monitoring operations as well as storing and forwarding operations to route the data that have been collected to a sink node. Acoustic communications are the typical physical layer technology in UWSNs as other mediums are not feasible to be used in the underwater environment such as radio waves and optical waves[1]. Each of these sensor nodes is equipped with acoustic modem and being deployed manually or randomly in deep or shallow water based on their application requirement. However there are several limitations and challenges in UWSNs because of the uniqueness of UWSNs compared to other networking environments like Terrestial Wireless Sensor Networks (TWSNs).

Due to the unique characteristic of underwater environment, there are several issues or challenges when talking about designing communication network in the underwater environment especially in designing the routing protocol. First, the deployment area in UWSNs which is using 3 dimensional architecture is so large. However due to the underwater sensor node is very expensive compared to the terrestrial sensor, the deployment of nodes is usually in sparse and the sensor nodes are suffered in the water movement[3-5]. Second, UWSNs sensor nodes are powered by battery; instead terrestrial sensor nodes use solar to extend power. In UWSNs nodes are solely powered by battery which cannot be recharged and difficult to be replaced due to water conditions[6]. This is the reason why designing energy efficiency routing is so important in UWSNs.

Third, by using the acoustic signal as a medium of communication, UWSNs is prone to long propagation delay, high path loss, limited bandwidth and high energy consumption compared to the radio signals used in TWSNs[1,7-9]. Finally, due to the inapplicable use of Global Position System (GPS) in UWSNs since the high radio frequency employed by GPS is rapidly absorbed in underwater environment, the procedure of placing and obtaining the location information of sensor nodes become very difficult in UWSNs compared to TWSNs[10,11].

Currently there are a number of published survey papers regarding the routing protocol in UWSNs[2,10,12-19]. However many of them are presented with the general view and standard categorization for routing protocols[12,20]. In [21], it is the first paper to talk about energy efficiency in UWSNs especially for routing protocol in network layer. This paper suggests that energy consumption in UWSNs is still an open issue to be investigated and further research should be conducted to increase the energy efficiency of UWSNs. Another paper [22] gives attention on reviewing the energy effiency and reliability in MAC and routing protocol for UWSNs. This paper suggests that the energy efficiency and throughput are different for different categories of protocols. As for OR protocol there are several papers $[23,24]$ that discuss more on how OR can be efficiently used in UWSNs environment. In [25], the author reviews that all energy efficient routing protocol belong to UWSNs either 
they are using OR or not.

In this paper, we focus more on energy efficient OR protocols that are designed for UWSNs and their features. Moreover, we discuss the main challenges of using OR protocols in UWSN from different perspectives and provide some future works in this field.

The rest of this paper is organized as follows. Section 2 provides basic information about UWSNs. Routing protocols for UWSN is presented in section 3. Energy efficient routing protocol for UWSNs is presented in Section 4. In section 5, a detailed classification of energy efficient OR is presented. Section 6 presents three tables of comparison of these protocols based on their features, performances and simulation parameters with complete segmentations. Finally in section 7 some future works and the conclusion of this paper are presented.

\section{Underwater Wireless Sensor Networks}

The underwater communication has begun since World War II where, in 1945 there were some underwater telephones being deployed to communicate with submarines in deep sea but since then only little work had been done which makes this underwater communication remains an unknown area. However recently, over the past decades this area of UWSNs received so much attention from researchers around the world who had begun the exploration in this area to monitor the marine environments for scientific, environment and navy tactical needs[26].

In the near future, UWSNs will take an important role in the future ocean surveillance system where the applications include the discovery of objects on the ocean floor, collecting scientific data, pollution control, environment monitoring and the transmission of images from remote sites which will benefit many of us. One examples of application is the tsunami monitoring system which is used to monitor the seismic movement of earth and able to provide tsunami warnings to the main land early[11,27,28].

\subsection{Communication Architecture in UWSNs}

The network topology UWSNS is generally one of the crucial factors for routing designs which can determine the energy consumption, capacity and reliability of a network. Based on the sensor mobility deployment, the network topology UWSNs can be divided into two categories which are static and mobile UWSNs[21].

\subsubsection{Static UWSNs}

The main characteristic of static architecture UWSNs is that the sensor nodes would be pretty static after the arrangement with each sensor is anchored either to the ocean floor (two dimensional UWSNs) or float with the fixed depth (three dimensional UWSNs)[5,10]. In two dimensional UWSNs, all the sensor nodes are anchored to the ocean floor while the sinks are deployed on the ocean surface. Each of the sensor nodes is equipped by the horizontal and vertical acoustic transceiver. The sensed data from the sensor node is forwarded to the intermediate gateways using horizontal link and later the underwater gateways aggregate the data and transmit to the surface sinks using vertical acoustic links. In three dimensional UWSNs, sensor nodes are equipped with acoustic modem and deployed in different depths of water. To control their movements, these nodes are anchored to the ocean bottom or surface buoys so that their movement are really small. The sink nodes are also deployed on water surface, which are equipped with acoustic and radio modems. The sensed 
data from the sensor nodes are transmitted towards the sink node via acoustic links in multi hop and the sink node receives and forwards the data into the base station off shore or on shore using radio links communication.

\subsubsection{Mobile UWSNs}

In comparison to the static UWSNs, a mobile UWSN is a self-organizing network by which the sensor nodes equipped with acoustic modems may be reorganized and moved by the water current. These sensor nodes are moved freely and the depth of these sensor nodes are controlled by the buoyancy. All sensed data are forwarded towards the sink at surfaces via multi-hop acoustic routes and the sink will transmit the data to base stations via radio waves communication [21]. As the mobile UWSN is a dynamic topology and requires more challenges in establishing communication compared to static UWSNs, more algorithms for underwater routing are designed for mobile UWSNs.

\section{Routing Protocols for UWSNs}

Routing is a fundamental task for any network and routing algorithm protocol is considered as finding and maintaining a suitable path of data delivery towards the sink from the source node. Previously most of the researches conducted regarding UWSNs focused on the physical layer medium and tried to tackle issues related to acoustic signals. However, working on the network layer in UWSNs, such as defining an optimal routing protocol algorithm is still new and needs to be addressed properly by researchers.

There are two main approaches commonly used in routing protocol for wireless sensor networks, namely end-to-end routing and OR[29,30]. End-to-end routing is a traditional routing way which has the complete routing table with the path of information from the source to the destination, while OR is a dynamic approach which uses hop-by-hop greedy flooding the data packet from the source towards the destination, which in this situation is called sink [29].

Compared to TWSNs, many routing protocols are proposed using end to end routing method which is path based[10]. In end-to-end routing method, a path from the source node to the destination node is found and then a single copy of data packet is forwarded towards the destination in hop-by-hop method using this path. However this routing method is not suitable for UWSNs due to the nature of UWSNs such as dynamic topology, harsh water environment, sparse deployment, higher propagation delay, higher energy consumption, high error links and three dimensional of underwater. Therefore, UWSN is a very dynamic network topology while OR is the most promising routing approach to be used in UWSNs $[10,23,29,31]$.

\section{Energy Efficient Routing Protocol in UWSNs}

Generally UWSNs sensor nodes suffer from limited power source by using the limited battery power. Up till now, researchers are still trying to solve this problem by using several methods like energy harvesting wireless sensor devices which convert mechanical, electrical or acoustic energy into energy for powering the sensors. However, this improvement of energy harvesting schemes is not sufficient and still in the infant stage which inccurs a lot of problems in the implementation[32]. So, in order to extend the life expectancy of UWSNs, it is very important to reduce the energy consumption during communication. Realizing the fact, a significant number of researchers has given attention to construct an energy efficient 
routing protocol in UWSNs.

As revealed earlier, OR is the most promising routing approach in UWSNs to date. However, by implementing OR, there are some issues like suffering from high traffic which can lead to a higher energy consumption and low network lifetime of the sensor node $[2,21,24]$. On the other hand, in recent years there are several OR algorithms being proposed to increase energy efficiency by reducing the travel of duplicated packets through suppression which can reduce traffic load in the network(Tariq et al. 2015; Wahid et al. 2014; Yu et al. 2016).

Currently most of the existing proposed routing protocols in UWSNs such as VBF [37], DBR [38], iAMCTD [39], Hydrocast [33] and WDFAD-DBR [36] are using OR approach in their routing protocols. Each of this OR protocols is using different techniques to reduce the traffic load and identifies the flooding area for forwarding the packet. In addition, each of these OR approaches has their own advantages and disadvantages.

Nevertheless, there is still a need to design an energy efficient OR protocol for UWSNs. For this motivation, the present research focuses on designing and developing energyefficient based on OR algorithm for UWSNs.

\section{Classification Energy Efficient OR Protocols in UWSNs}

OR protocols are comprised of two main blocks which are candidate set selection (CSS) and candidate set coordination (CSC) [24] . Each of these blocks has their own procedure to make sure this OR can function well in the network. For CSS blocks, this procedure is responsible in selecting a candidate as the next-hop forwarder to forward the packet towards the sink or destination. There are three types of CSS, which are sender-side-based (SSB), receiver-side-based (RSB) and the last one hybrid approaches [24]. In SSB, the candidate set is determined by the current forwarding node when there are data to be transmitted. In $\mathrm{RSB}$, the candidate set is determined by the neighbours where each neighbour will be responsible in validating whether it is a candidate for next hop forwarder. For hybrid approach the candidate set is determined cooperatively by the current forwarder node and its neighbours.

In Fig. 1, energy efficient OR protocols are classified based on three types of CSS, which are SSB, RSB and hybrid approach. Each of these types is divided into two more subcategories namely location based and location free.

\subsection{Sender Based Approach (SSB)}

In SSB, the set of next hop candidate is determined by the current forwarding node when there are data to be transmitted. Based on the algorithm determined by the source node, the next hop forwarder is being selected. There are a number of OR protocols which belong to this category. Each of them is divided into 2 subcategories based on their required location informaton; location based and location free. Next we provide more in-depth explanation of these routing protocol with their methods and how they belong to this category. 


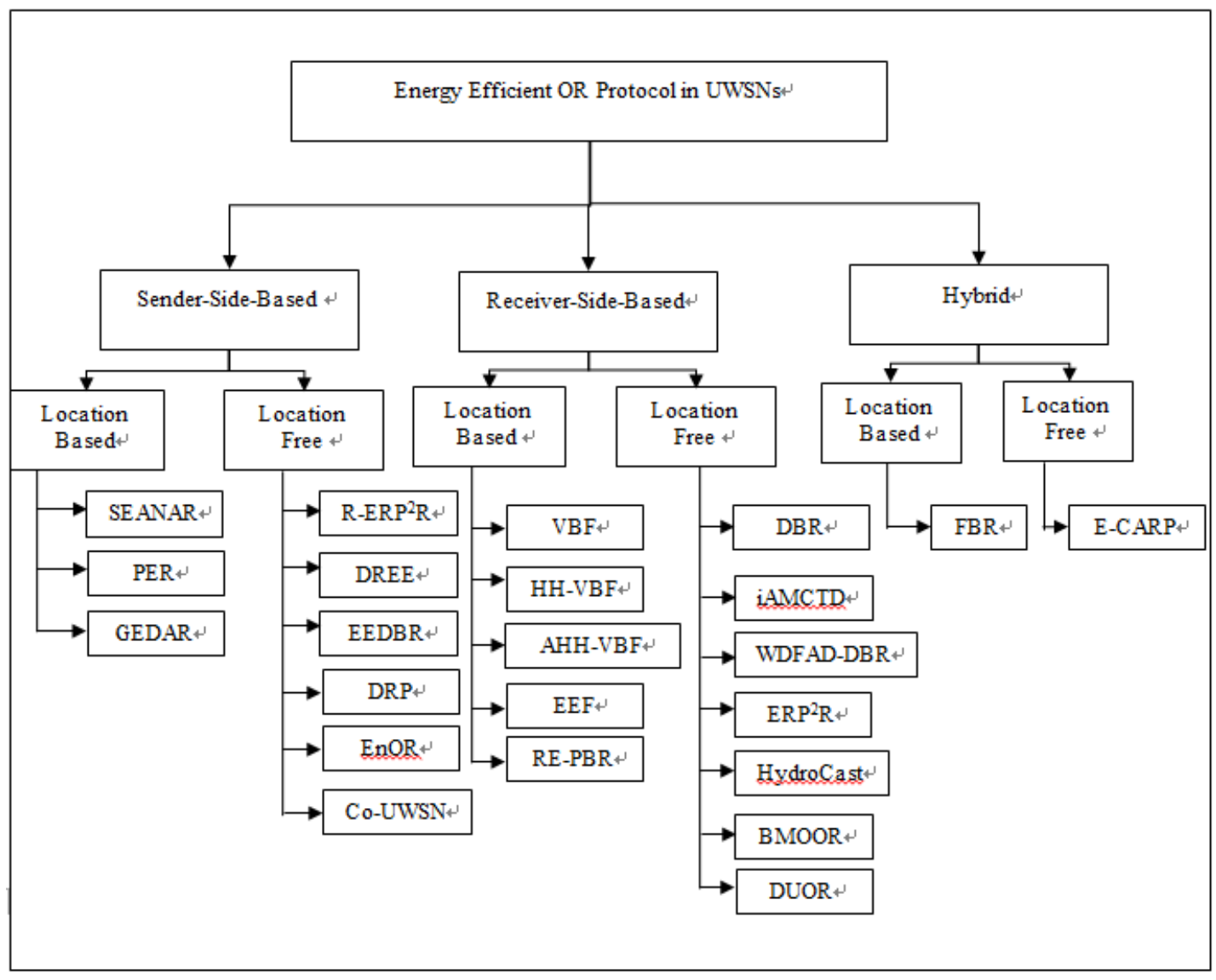

Fig. 1. Classification of Energy Efficient OR Protocol in UWSNs

\subsubsection{Location Based}

All routing protocols that belong to this subcategory need the location information of their sensor nodes during the implementation of network in UWSNs. Next is the detailed explanation about the routing protocols and why they belong to this subcategory.

\section{SEANAR[40]}

The main purpose of SEANAR is to obtain a high delivery ratio with low energy consumption while handling the mobility of nodes. SEANAR is composed of two phases: neighbours' information maintenance phase and data sending phase. In the first phase, each node periodically broadcasts a location message including its node ID, location, and residual energy. If the receiver node is located in the inner or aside layer, it updates its inner neighbour table or its aside neighbour table; otherwise, it simply discards the message. Consequently, the degree of each node is computed by counting the number of nodes in the inner and aside tables. Fig. 2 shows the spherical layers used in this protocol. 
In the second phase, each sender node sends a hello message including the node ID, packet sequence number, and layer information. Upon receiving the message, each node looks at the layer information. If the sender node is located in the inner layer, it simply discards it; otherwise, it replies an acknowledgment message including its node ID, distance to sink, inner degree, aside degree, and residual energy. When all acknowledgment messages are received by the sender node, it calculates their weight and selects the node with the largest weight as the forwarder node and sends data packet to this node. As this belongs to the SSB subcategory, the sender node is responsible in choosing the next forwarder node.

However, one of its important weaknesses is that it uses fully the location information of nodes in routing, which can be so costly. In addition, it does not benefit from the advantages of multisink architecture which causes rapid drain in the battery of those nodes located closer to the single sink. Weights of neighbour nodes are calculated in each hop of data sending phase by sending the received messages to neighbouring nodes which cause end-to-end delay and increase energy consumption, especially in dense deployments. Furthermore, the period of time when the first phase should be repeated has a direct impact on the protocol performance.

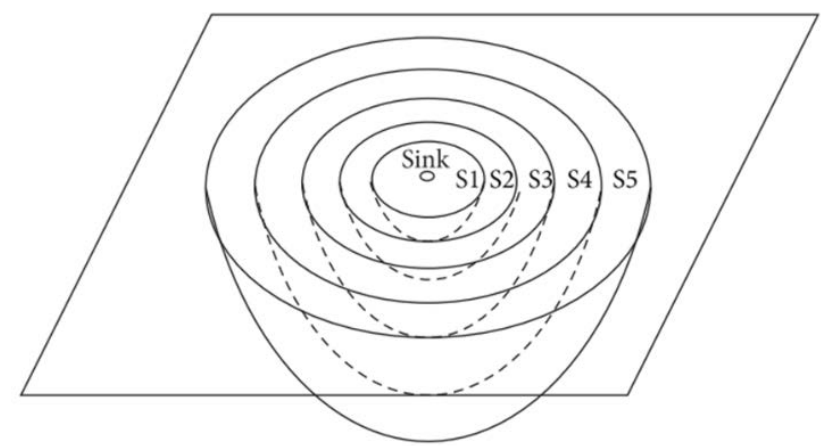

Fig. 2. Layering SEANAR

\section{Power-Efficient Routing (PER)[41]}

In the architecture of UWSNs, ordinary nodes are randomly distributed in the fascinated volume which can move in uninformed directions, and the source node is deployed at the bottom of the water. In addition, a stationary sink is located in the centre of the fascinated volume on the water surface. The main goal of this protocol is to reduce the energy consumption of communication. It is composed of two main modules, namely forwarder node selector and forwarding tree trimming mechanism.

In the first module, each forwarder node selects two appropriate next hop nodes among its neighbour nodes by employing fuzzy logic technique. In this module, the fuzzifier is fed by three parameters, including distance, residual energy and the angle between two neighbouring nodes in order to generate linguistic values. Then, these linguistic values are given to defuzzifier in order to generate nonlinguistic values. Finally, the source node will select two best next forwarder hop nodes based on the result of defuzzifier and sends data packets to them which explains why this routing protocol belongs to SSB.

The module of forwarding tree trimming mechanism is suggested to reduce power 
consumption. In this module, a limitation is applied based on the number of duplicated packets received in each node. If the number of duplicated packets is bigger than a predefined threshold, the forwarding tree trimming mechanism is employed; otherwise, data packet is sent to the two selected next forwarder hop nodes. The forwarding tree trimming mechanism decreases the number of redundant packets, which results in less overhead and less energy consumption.

However, PER routing protocol has some drawbacks; for example, it needs location information, which is very costly and difficult to acquire in underwater environments. Additionally, it employs a single sink architecture, which causes rapid drain in the battery of the nodes that are closer to the sink. Although the communication void hole is a critical problem in the OR implementation, this problem is not being handled in PER.

\section{GEDAR [42]}

GEDAR uses an opportunistic routing protocol forwarding strategy in which sensor nodes broadcast data packets to multiple sinks in their transmission range. While, if the source node did not find any neighbour in its progression area then the recovery procedure would adjust the depth of a sensor node to new depths in order to find a next hop forwarder node. During the data forwarding phase, at each hop sensor nodes would propagate a beacon messages to locate a next hop forwarder node with minimum distance than the current node with respect to the sink. It takes advantage of the opportunistic routing redundant transmissions for reliable data packet delivery at the destination. GEDAR achieves high packet delivery ratio, avoids void holes, and also provides the recovery mechanism (depth adjustment) to recover data from a void region. However, the main drawback for GEDAR, it uses the location information, which is very costly to get in underwater environment.

\subsubsection{Location Free}

In this subcategory, all the routing protocols do not require the location information of the sensor node. They can operate the network without knowing the exact location of the next forwarder. Below is the detailed explanation regarding the routing protocol that belongs to this subcategory.

\section{R-ERP ${ }^{2} \mathbf{R}[35]$}

The R-EPR ${ }^{2} \mathrm{P}$ is an enhanced protocol from $E P R^{2} \mathrm{P}$ that uses the physical distance, residual energy and link quality value to add reliability. It consists of three phases; initialization phase, data forwarding phase and maintenance phase. In the initialization phase, the sink node broadcasts beacon messages containing physical distance and residual energy information. Any node receiving the beacon messages would compute its own distance towards the sink using time of arrival (TOA)/ Time difference of arrival (TDoA) mechanism. A node then embeds its own distance to the sink in the packet and further rebroadcasts the packet to their neighbours' node. The process goes on until all nodes have computed the distance towards the sink and at same time calculated the link quality towards it neighbours.

In the data forwarding phase, as this protocol is a sender-based protocol, when a sensor node has data packets to send, it computes the cost and chooses a next hop neighbour with good link quality having high residual energy. Later data packets are forwarded from each source to the sink. Maintenance phase is performed periodically to update the physical distance, ETX values and residual energy information of each of the nodes. 
R-ERP ${ }^{2} \mathrm{R}$ shows a better performance over its predecessor and other protocols in terms of delivery ratio, end-to-end delay and energy consumption. However this protocol still has some weaknesses. Due to the dynamic network of UWSNs, the maintenance phase should be done repeatedly and can incur a high network overhead. Another is, although communication void is a critical problem in OR, this protocol does not consider this problem in their algorithms.

\section{DREE[34]}

The DREE protocol is a single path which employs 3D UWSNs architecture with multiple sink nodes at the water surface and ordinary nodes are randomly deployed at different depths underwater. DREE uses F-LQE as the link quality metric in addition to physical distance and residual energy. DREE has three phases; first network initialization phase, second data forwarding phase and last maintenance phase.

In network initialization phase, all sink nodes broadcast Hello packets containing their ID, residual energy and physical distance information at the same time. Each node receiving the packets will compute its distance towards the sinks and later rebroadcast the packets to their neighbours with own added cost information in the packet. If a node receives more than one packet from different sinks, it will only adopt the shortest distance towards the sink.

In data forwarding phase, since this is a sender-based protocol, when a source node has data packets to send, a node will select a single most reliable forwarder based on the physical distance, link quality and residual energy of the node. Each node will only store the information of neighbouring nodes having less distance to the sink than itself. On successful selection of the next hop relay node, the source node embeds its ID in the NEXT HOP field of the data packet. Only the node in the Next Hop field will forward the packet, others will simply discard the packet. In maintenance phase, due to water current and battery drain, the hello packets will broadcast from the sink every 75 s to update the distance, residual energy and F-LQE of each of the node through the network life.

There are several advantages of DREE, including that this protocol works without using any localization information for forwarding the data packet. It also employs multi-sink structure which can prevent the rapid draining of nodes closer to the sink. However, this DREE also has some drawbacks, first in the dense network, the number of next hop forwarder will increase remarkably which can cause very high energy consumption. Although communication void is a critical problem in OR, this protocol does not consider this problem.

\section{EEDBR[43]}

The aim of this protocol is to balance the energy of nodes and prolong the network lifetime. EEDBR is a sender-based routing protocol in which the sender node selects a set of next hop nodes based on their depths and residual energy information. EEDBR consists of two phases: knowledge acquisition and data forwarding. The knowledge acquisition phase will share the information to the neighbour sensor nodes with its Hello packet format, which consists of Sender ID, Residual Energy, and Depth. Therefore, all neighbour sensor nodes collect and save their neighbouring nodes' information. The nodes with smaller depths are only involved in data forwarding mechanism.

In the second phase, a subset of forwarder nodes are chosen based on their depth information and residual energy. In other words, as this protocol is sender-based, a group of 
neighbouring nodes with a smaller depth than that of the sender node that has appropriate residual energy are chosen as the candidate of next hop forwarding node. The selection of neighbour nodes for data forwarding mechanism is based on residual energy. This selection criterion will balance the energy consumption between sensor nodes. The packet holding time is based on residual energy. Fig. 3 shows the example on how next hop candidate is chosen in EEDBR.

However, this protocol also has some weaknesses; the knowledge acquisition phase should be repeated in short interval time due to the high movement of sensor nodes with water flow, which can cause really high communication overhead in the network. This protocol also does not take in link quality information between sensor nodes, while it is a vital parameter in UWSNs due to unpredictable acoustic links. Although the communication void problem is a common problem in OR, EEDBR does not suggest a solution to tackle this problem.

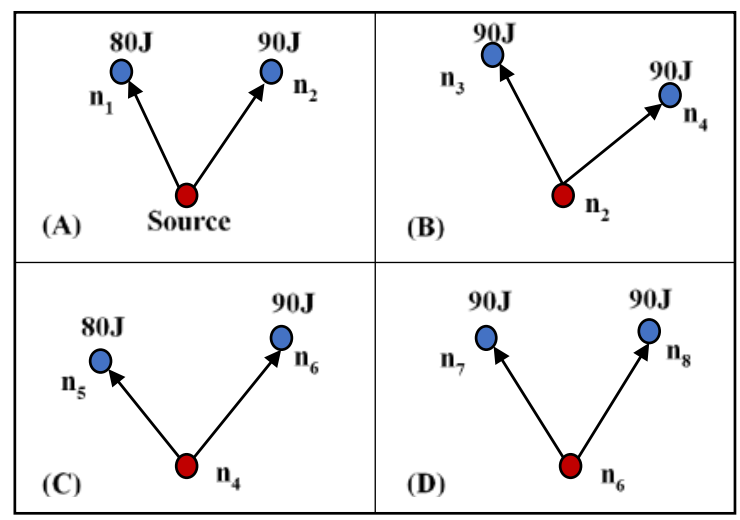

Fig. 3. Next candidate selection process in EEDBR

\section{RE-PBR [44]}

The RE-PBR hasintroduced the link quality estimator as one of the metric uses for ranking the node in forwarding set for pressure-based routing protocol. RE-PBR is consisted of two phases, namely information acquisition and data forwarding phase. During the information acquisition phase, each nodes would share their depth and residual information among the shallower next hop node. Link quality would be calculated during this phase to be included in route cost calculation later. The next hop node would be ranked by the calculation route cost based on value of link quality and residual energy for all shallower nodes. Due to the continuously movement of node, this information acquisition is run periodically to update their latest information to each shallower next hop node.

During the data forwarding phase, the sender node would only select the best candidate forwarder node based on minimum route cost value. The receiver node would only forward the packet if their id embedded on that packet, while other node will simply discard it. The main drawback of RE-PBR, as selecting the only one next 
hop node would increase the likelihood of retransmission to occur. Therefore, the energy consumption and end-to-end delay significantly increase. Another one, although communication void is a critical problem in OR, this protocol does not consider this problem in their algorithm.

\section{DRP [45]}

This protocol is actually the distance-vector based routing protocol which employs the transmission distance and residual energy on selecting their next hop forwarder candidate. It's using the localization schemes to obtain the distance between 2 nodes. This protocol is using the beacon messages to obtain all the route information from node to the sink. Sink node would periodically broadcast the Hello messages to the sensor node and the nodes would update their information. Later the route for all nodes to sink could be built based on the distance and residual energy information. This protocol also is the first protocol using the transmission collision probability in their selection of path towards the sink.

The advantages of this protocol are using the residual energy as one of the criteria for selecting the best path towards the sink. However because it employs the beacon messages algorithm, it would need to periodically update the route information. This action could lead to higher energy consumption.

\section{EnOR[46]}

This protocol is introduced as baseline lightweight energy aware protocol, which aims to balance energy consumption and prolong the UWSNs network lifetime by rotating the forwarding candidate nodes based on their residual energy, link reliability and packet advancement. This protocol employs two main procedures, candidate set selection and candidate transmission prioritization. In candidate set selection, each node would periodically broadcast a beacon packet to one hop neighbour with their residual energy and depth local information. Whenever the node receives the beacon packet, it will update their neighbouring table.

Once the sender had the packet to transmit, it would calculate the fitness value of all their neighbouring nodes and select the most appropriate among them. The candidate node would be ranked based on fitness value calculated from link reliability, packet advancement and residual energy. Next the transmission priority level would change accordingly to residual energy which is low energy means low fitness value, high energy higher fitness value. EnOR is using timer based coordination for prioritization the candidate node during the forwarding phase. Each node receives the data packet for forwarding would calculate their own packet holding time based on fitness value. Another good feature in EnOR is using active packet suppression where, once the sender overheard the packet id sent by the forwarder node, it will send the short suppression signal to make sure the low priority node would cancel their transmission. However, this short signal would overload the network and could lead to higher energy consumption. 


\section{Co-UWSN [47]}

The Co-UWSN is a protocol proposed using cooperative communication among nodes that combats fading in data transmission process. Signal strength and distance information are used for basis selection of relay nodes. During the initialization phase, sink nodes broadcast hello packet in the network to get vital information like residual energy, distance and signal strength. Every 50 round the sinks will broadcast hello packets again to update the information and remove a dead node in network. To reduce path-loss effects and increase network lifetime, this protocol exploits a single hop and multi-hop transmission. Therefore, a significant decrease in path loss as a result, improved throughput and better data integrity.

However, due to dynamic network UWSNs, maintenance phase should be repeated and can make network overhead high which consumes more energy.

\subsection{Receiver Based Approach}

In RSB, the next hop candidate set is determined by the neighbours node inside their transmission range but each neighbours node will be responsible in validating whether it is a candidate for the next hop forwarder. In this category, there are several candidates for the next hop forwarder, where each of them will calculate its own holding time based on the routing protocol algorithm. Therefore, any nodes having small holding time will forward the data while other nodes that receive the same packet would discard the packet. So in this case, not all next hop candidates will forward the data packet which can reduce the transmission load. There are a number of OR protocols which belong to this category. Each of them is also divided into 2 subcategories based on their need of location information; location based and location free. Next we provide more in-depth explanations of these routing protocols with their methods and how they belong to this category.

\subsubsection{Location Based}

All routing protocols that belong to this subcategory need the location information of their sensor nodes during the implementation of network in UWSNs. Next is the detailed explanation about the routing protocols and why they belong to this subcategory.

\section{Vector Based Forwarding (VBF)[37]}

The VBF is an opportunistic geographical location information routing protocol based on mobility and does not require the state information of the sensor nodes. VBF is proposed as a solution to two important problems in underwater environment, namely the continual movement of ordinary nodes by water current and energy efficiency. In VBF, each source node creates its own pipeline towards the sink and embeds its sink location, and its own location as a forwarder node in the packet and broadcasts this packet. As this protocol belongs to the receiver-based subcategory, all the sensor nodes are responsible in identifying 
their eligibility to forward the data. After receiving a packet, the sensor node having less distance than the radius of the vector can forward the packet by updating the forwarder node information, otherwise, it simply discards the packet.

Through the node forwarding mechanism only few nodes are involved in the packet forwarding which focuses on the scalability and robustness of the VBF. As only few nodes are involved in forwarding the packet, the network traffic and energy consumption decrease significantly. Fig. 4 shows the virtual pipeline for forwarding the packet.

However, VBF has several drawbacks: the performance of this protocol is directly dependent on the radius of vector and the radius of pipeline plays the main role in VBF. VBF has no ability to recover the void region nodes which might happen in sparse deployment, if any node goes to the void region then it discards the packets.

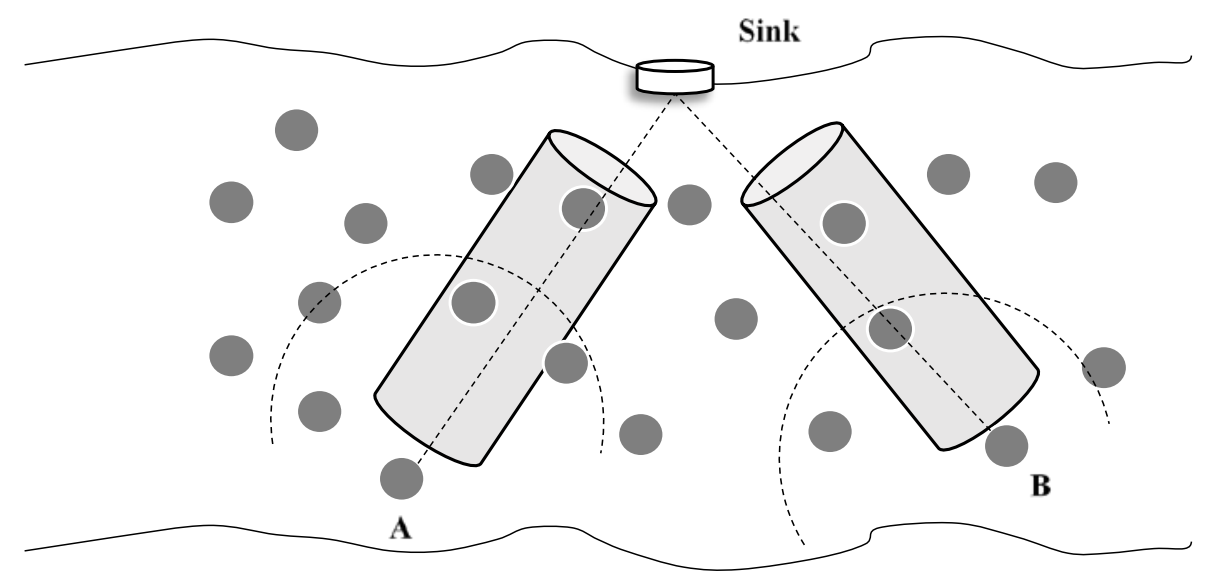

Fig. 4. Virtual pipeline for each node in VBF

\section{HHVBF[48]}

$\mathrm{HH}-\mathrm{VBF}$ is an enhanced version of $\mathrm{VBF}$ proposed to improve the probability of communication void in sparse environments in order to increase successful data delivery. In addition, it needs a smaller radius than VBF in finding eligible forwarder nodes while causing an improvement in the packet delivery ratio. HH-VBF uses multiple virtual pipes from the source to the destination nodes. In HH-VBF the vector is computed on per-hop basis i.e. each forwarding node computes a vector from itself towards the sink. As this $\mathrm{HH}$ VBF is also receiver-based, the eligible sensor node for forwarding is determined by the sensor node based on the radius range computed by the previous forwarder node. Fig. 5 shows how the virtual pipeline is created for each hop.

However, due to the hop-by-hop transmission method, the overheard is heavier than in VBF; moreover, the performance of HH-VBF is sensitive to the vector radius threshold and $\mathrm{HH}-\mathrm{VBF}$ cannot handle void area region effectively. 


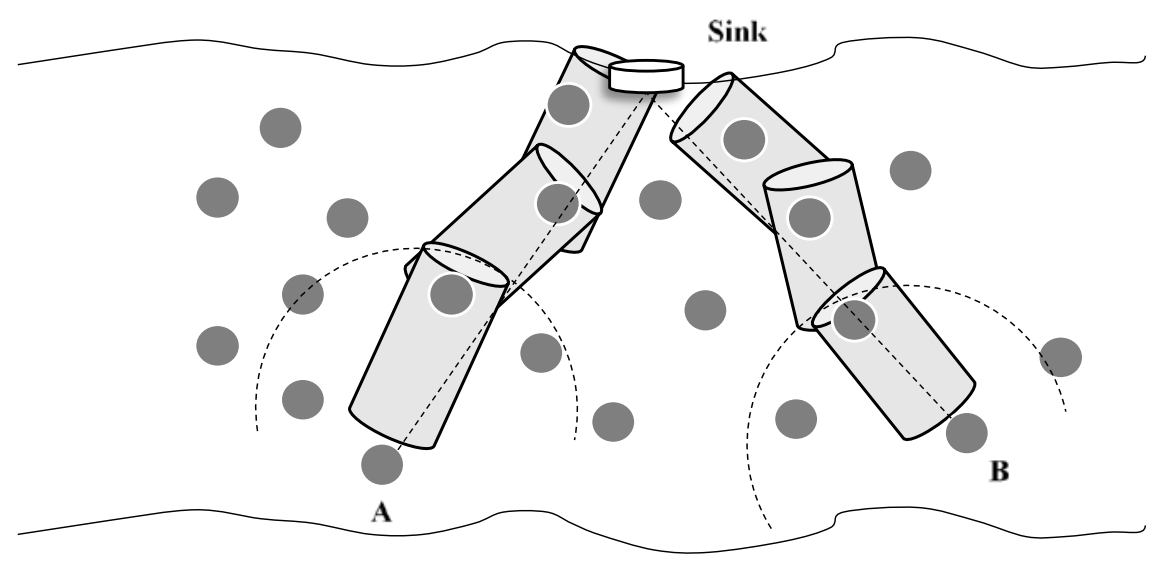

Fig. 5. Virtual pipeline for each hop in HH-VBF

\section{AHH-VBF[49]}

This routing protocol is based on HH-VBF but dynamically adjusts the radius forwarding pipeline and the transmission power according to the deployment of sensor node with the objective of conserving energy to prolong the network timeline. AHH-VBF is deployed based on the single sink architecture which comprises anchor node, relay node and sink. Unlike the HH-VBF, the radius pipeline and transmission power is dynamically changed at every hop based on the sensor node distribution. AHH-VBF is proposed against the solution of using static radius pipeline and transmission which has some disadvantages such as degrading the network performance in a long run.

AHH-VBF is a receiver based protocol, which each eligible neighbour would calculate their own holding time based on the information from data packet. The data packet will be forwarded once the holding time expired or discarded after overheard the same packet in networks. By implementing this algorithm, this routing protocol can ensure minimum duplicated data packets in the networks. Their simulation show that this perfomance protocol has outperformed the HH-VBF based on the energy tax and delivery ratio in the same environment.

However, this protocol also has some weaknesses; this protocol is using location information yet it is very difficult and sometimes impossible to get the location information of sensor node in underwater environment. Even though this protocol does not update the information of the node regularly but this protocol has the worst performance in sparse network because it needs more than 2 nodes to be able to forward the data.

\section{EEF[50]}

EEF is proposed to prolong network lifetime and to lessen end-to-end delay in UWSNs by calculating the fitness value using residual energy, depth and distance from the sink node. EEF is a hybrid location-based and location free pressure-based routing algorithm. In EEF, it 
is assumed each sensor node has its own location information as well as the location information of the sink node.

In EEF, when each node wants to forward a data packet, it calculates the sender fitness value and location information. Then, it embeds the sender ID, sender fitness value, location information of sender, and location information of destination into the data packet and broadcasts the data packet to its one-hop neighbours. As this procotol is receiver-based, each receiver node would compute its fitness value and then compares its fitness value with the sender fitness value from data packet. If its own fitness value is greater than sender fitness value, it participates in packet forwarding process. Otherwise, it simply discards the packet. The lowest holding time is computed based on the higher fitness value of node.

There are a few main drawbacks in EEF. First, EEF uses the full location information of sensor nodes to handle the candidate set selection and ranking, while finding this information is so costly in UWSNs. Second, the EEF suffers from a lack of communication void handling algorithm which is a common issue in OR.

\subsubsection{Location Free}

In this subcategory, all the routing protocols do not require the location information of the sensor node. They can operate the network without knowing the exact location of the next forwarder. Below is the detailed explanation regarding the routing protocol which belongs to this subcategory.

\section{DBR[38]}

DBR is the first pressure routing protocol proposed for UWSNs. In this protocol, each node is equipped with an economical pressure sensor to calculate locally the depth of the sensor node. DBR is using only the depth information to perform routing in UWSNs. DBR employs 3D UWSNs architecture with multiple sink nodes at water surface and ordinary nodes are randomly deployed at different depths underwater. In this protocol, the routing idea is very simple, where each of the node having less depth from the sender is the candidate node to forward the data.

In DBR, each sender node embeds their own depth in data packet and broadcasts it to onehop neighbours. Once the neighbouring node receives the data packet, it compares with its calculated depths. If its depth is less than that of the sender node, it is the candidate node for forwarding; in contrast it just discards the packet. Fig. 6 shows the process of candidate node selection in DBR. In order to prevent high network overhead and retransmission, as this protocol is receiver-based, each candidate node would compute a holding time based on their depths and the sender node depth. So each node has different holding time. Each node will wait until their holding time expire, then it will forward the data packet. While in this period, if the same packet arrives from a lower depth node, it just removes the packet from the sending queue. Each of the successfully transmitted packet will be added to the packet history buffer.

In DBR the number of duplicated data packets is shared by sensor nodes which results in a high transmission delay, high volume of packets collision and energy consumption. Although the communication void problem is a common problem in OR, DBR does not suggest a solution to tackle this problem. 


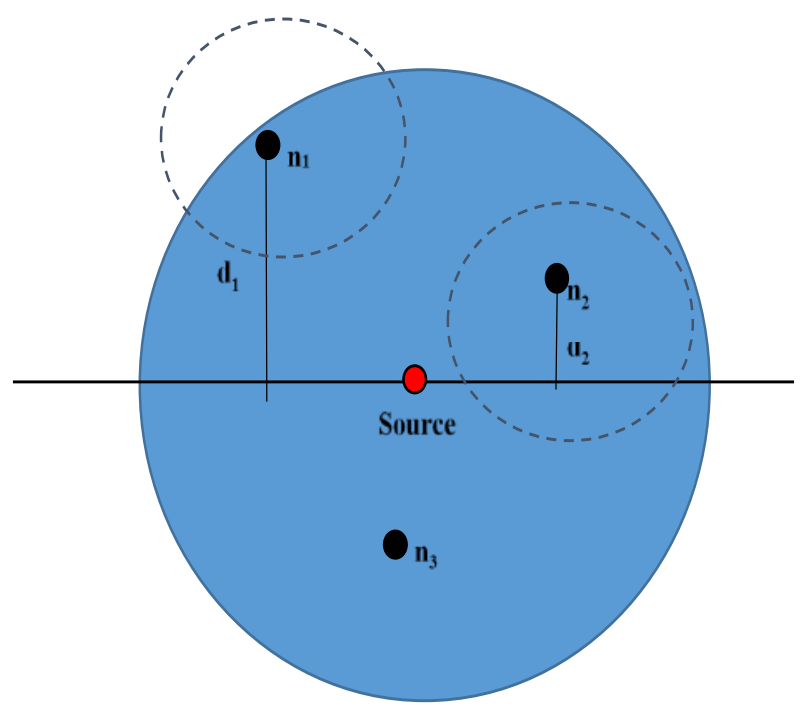

Fig. 6. Candidate node selection in DBR.

\section{iAMCTD[39]}

iAMCTD is a forwarding-function FF-based routing protocol. iAMCTD is suitable for delay-sensitive applications due to variation in depth-threshold which increases the forwarders. It maximizes the lifetime of reactive UWSNs by optimizing the mobility pattern of the sink. iAMCTD consists of 4 phases; network initialization and underwater channel, implementation of on-demand data routing, data forwarding and adaptive mobility pattern of courier nodes.

The first phase deals with sensor nodes' deployment and network initialization. During knowledge acquisition, nodes share the depth and residual energy information among themselves. As the network initiates, courier nodes remain at equal horizontal distances from each other and these initiate vertical movement towards the bottom. The second phase is the implementation of on-demand data routing to facilitate time-sensitive and critical-data applications. The third phase of data forwarding is using efficient forwarding functions for optimal data forwarding along with the variations in depth thresholds for sensor nodes to cope with varying network density in UWSNs. On the basis of control packets, the sink identifies the network density and manages the network specifications and mobility of courier nodes. The last phase uses mixed integer linear programming (MILP) to analyse adaptive mobility patterns of courier nodes and their multiple cases.

Throughput in iAMCTD is decreased as it avoids unnecessary data transmissions. In iAMCTD, an optimized sink mobility is introduced to minimize end-to-end delay for delay sensitive applications. The optimized mobility of the sink in iAMCTD also minimizes delay in sparse conditions. However there are some issues with iAMCTD. First, the use of courier nodes significantly increases the network cost because these nodes are so expensive. Second, the movement pattern of courier nodes plays a vital role in handling void areas and the performance of routing algorithm.

The main drawback of energy efficient routing algorithms, which employs the mobilerelay node approach, is that the AUVs or courier node is so costly and employing these 
nodes impose high cost to network implementation. In addition, finding the optimal number of AUVs and their movement pattern is a great issue in UWSNs that suffer from sparse and high dynamic network topology.

\section{$\operatorname{ERP}^{2} \mathbf{R}[51]$}

The ERP ${ }^{2} \mathrm{R}$ employs a 3D architecture in which the multiple sinks are located on water surface and ordinary nodes are dispersed randomly in different depths under water. It has 2 phases, which are cost establishment and data forwarding. In the first phase, each node will assign the cost based on their physical distance to the sink. Sink nodes will broadcast a hello packet including the sender ID, residual energy and cost towards their neighbouring nodes. Each node receiving the hello packet will update their own residual energy and calculate the cost and later rebroadcast the hello packet including their information towards their neighbouring nodes. Finally each of the nodes will have their physical distance towards the sinks.

In the data forwarding phase, each forwarder will broadcast to their neighbours based on the sorted list of its neighbours' ID which has a smaller cost than the forwarder node. The priority will be based on the residual energy and cost node, while the holding time will be computed based on that too. Higher priority node with zero holding time is equal to zero while other nodes will have calculated the holding time. As this protocol is receiver-based, priority nodes will forward the data once their computed holding time expires, while the other nodes will discard the data packet once they overhear the same data packet in networks.

There are several advantages of $\mathrm{ERP}^{2} \mathrm{R}$ : by employing the multiple sink approach, rapid battery draining at nodes located closer to the sink is being prevented and does not require location information of the nodes. However, the first phase should be done from time to time due to the movement of node in water current, which results in an increased network load. Although communication void is a critical problem in OR, this protocol does not consider this problem.

\section{HydroCast[33]}

HydroCast is a stateless and pressure protocol which prefers the inexpensive distributed localization. HydroCast utilizes the depth information along with relevant clusters through pressure levels. HydroCast forms the clusters without hidden information of terminal nodes. HydroCast has two modes, including OR mode and void handling mechanism.

In the first mode, an OR forwarding mechanism is used. This mechanism selects a subset of neighbouring nodes with positive advancement towards the sink as a next hop candidate to maximize the forwarding progress. In this process, it takes into account the expected packet advance (EPA) metric to select the higher link quality neighbouring nodes and hidden terminal problem to suppress the redundant packet forwarding by the nodes in the subset. Each forwarder node embeds the ID of candidate nodes in a data packet and broadcasts it. After a neighbouring node receives the data packet, it retrieves the list of IDs in the data packet. If its ID is not on the list, it simply discards the packet. Otherwise,as this protocol is receiver-based, it would calculate a holding time and sends a data packet based on this holding time. It should be noted that if it receives the same packet from a higher priority node in the holding time, it suppresses the data packet forwarding to prevent redundant packet forwarding.

In the second mode, void handling mechanism is employed in order to deal with 
communication void. When a node does not have any neighbour with a depth lower than that of itself, it cannot employ the greedy routing; hence, this node is considered as a local maximum node. In this situation, it enables a void handling mechanism to deal with this problem. In this mechanism, the local maximum node finds and stores a detour path to a node with a depth lower than that of itself and transmits the data packet to this node. Finally, the data packet reaches a node that is not a local maximum node, and this node sends the data packet in OR mode.

HydroCast can handle the communication void problem which can enhance data delivery ratio. However, in HydroCast multiple numbers of same data packets are received by the sink node which leads to extra load on the network. Furthermore in HydroCast the energy efficiency parameter is not clearly defined.

\section{WDFAD-DBR[36]}

WDFAD-DBR is proposed to reduce the prospect of encountering void holes problem in UWSNs. WDFAD-DBR improves the communication reliability in sparse regions of the network through the advanced sensing of void holes. It also reduces energy consumption in dense regions of the network by dividing forwarding regions according to the nodes density and channel condition. WDFAD-DBR employs a multi-sink UWSNs architecture which is composed of anchored nodes, relay nodes and sink nodes. WDFAD-DBR makes forwarding decision according to the weighting depth difference of two-hop nodes and adaptively change the forwarding area based on the node density and channel condition. As this protocol is receiver-based, each node would compute the holding time and waits until the timer expires before forwarding the data. While in wait, if there is any other node sending the packet, the node would drop the packet and update the information. WDFAD-DBR also employs neighbour node prediction mechanism based on the history information on neighbours in neighbour table to improve the performance of the network. This technique also ensures a balanced energy consumption through forward area division to minimize load on the network.

However, WDFAD-DBR still suffers from some issues, including that the mechanism proposed in this protocol is not suitable for data sensitive applications. In addition, WDFADDB is not only using current node depth information but also depth information of the next expected node which is a very complex algorithm in UWSNs.

\section{BMOOR [52]}

The aim for this protocol is to minimize the delay and maximize the delivery ratio by using single sink architecture. Called as Balance and Multi-objective Optimized Opportunistic Routing (BMOOR), it operates in four phases which namely as, initial beaconing, dynamic lifetime estimation based and confirmation, route estimation and Bat based route optimization. This protocol is receiver based approach which each of forwarder next hop list can accept or withdraw from forward the data packet based on their residual energy. This protocol is using the Bat based route optimization algorithm to choose the best path among the set of possible paths to the sink.

By using the energy balance techniques, this protocol could ensure that the nodes stay alive in long period. However because of this protocol employs single sink architecture, it does not benefit from the advantages of multisink architecture which would cause rapid drain in the battery of those nodes located closer to the sink. 


\section{DUOR [53]}

DUOR is introduced to minimize signaling cost, solved the void area and extremely long forwarding path issue. This protocol belongs to the beacon-based and pressure-based combined routing protocol. It consists of four step, first, every node updates its own hop count, second, sensor node sends the packet, third, intermediate nodes forward the packet and lastly, sink node receives the packet. During the first step, sink node would broadcast the query frame periodically with includes query id, hop count and depth. Each node receives the query frame will compare the query id with store query id, if new one, node would update the hop count and depth information and later broadcast back the updated query frame, otherwise it simply discards it. The process is repeated until all the sensor nodes receive the query frame. During the sensor node sends packets step, the node would send the packet with their hop count and depth information.

During the intermediate nodes forward the packet, each node receives the forwarded packet would compare their hop count and depth information. If the node had less depth and low hop count, it would be candidate for forwarding the packet, otherwise it drops the packet. The highest rank node based on depth and hop count would transmit the packet while other lower rank node would suppress it when overhear the packet from highest rank. The main drawbacks of DUOR are: due to dynamic topology in the UWSNs, sink node broadcast query frame should be run in short intervals to update hop count and depth information, which would increase the network overhead and energy consumption.

\subsection{Hybrid Approach}

In hybrid approach the candidate of next hop forwarder set is determined cooperatively by the current forwarder node and its neighbours which is by using the control packet like hello message before sending the actual data packet. Below are the details of the routing protocol which belongs to this category.

\subsubsection{Location Based}

The routing protocols that belong to this subcategory need the location information of their sensor nodes during the implementation of network in UWSNs. Next is the detailed explanation about the routing protocols and why they belong to this subcategory.

\section{Focus Beam Routing (FBR)[54]}

FBR is an example of the hybrid approach where the sender and next candidate of hop forwarder are communicating with each other before the transmission occurs. In this protocol, it is assumed that each node knows its own location position and the location of sink. Since each power level has a different radius and a lower power level has a smaller radius and less energy consumption, the basic idea of this protocol is the use of different power levels to reduce energy consumption per bit. As the FBR uses the power level in the routing procedure, it is also considered as a cross-layer routing protocol. FBR applies 3D architecture in which four stationary sinks are deployed at the corner of the interested area and the ordinary node is randomly scattered in the area. Fig. 7 shows the process of FBR finding the next hop candidate.

In order to send a data packet, each node creates a cone with angle $\varnothing$ towards the closer 
sink node and sends a request to send (RTS) messages with power level P1. If the receiver node is located in the cone which is deriving from the sender node towards the sink, it replies a clear-to-send (CTS) message including its name and location information; otherwise, it simply discards the RTS message. The sender node waits for a specific time to receive the CTS messages. If it receives a number of CTS messages, it selects the one closer to the sink as the next hop node sends data packet to the node. The next hop node acts similar to the last sender node, and the data packet finally reaches the sink. Otherwise, it increases its own power level and sends a new RTS message. This procedure is repeated until a neighbouring node in the cone is found or the power level increases to P1. If there is no neighbouring node in the cone with power level P1, the cone can be rotated to the left side or right side, and the same procedure is repeated.

However, FBR has some serious drawbacks; it supposes that each node knows its location position and that of the sinks, while GPS simply cannot work properly in underwater environments, and the use of other localization techniques is so costly. The performance of FBR is very sensitive to the angle $\varnothing$. In other words, the angle $\varnothing$ should be large enough in sparse deployments to decrease the likelihood of failure while the angle $\varnothing$ should be small in dense deployments in order to reduce the network overhead and energy consumption. In order to detect and handle the communication void in FBR, each node should transmit the RTS message in all of its power levels one by one, which causes high energy consumption.

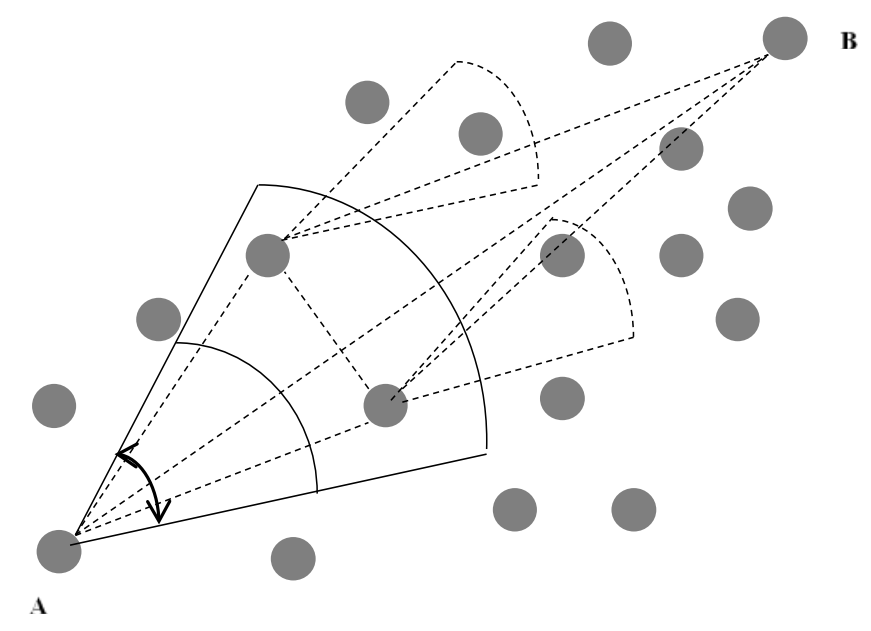

Fig. 7. Process to find next hop candidate in FBR.

\subsubsection{Location Free}

In this subcategory, all routing protocols do not require the location information of the sensor node. They can operate the network without knowing the exact location of the next forwarder. There is only one protocol that belongs to this subcategory.

\section{E-CARP[55]}

E-CARP is the routing protocol OR that employs hybrid approach in the routing process. ECARP is the enhanced version of CARP which uses channel aware routing protocol and OR. This protocol wants to improve CARP for routing the packet, while reducing the energy 
consumption and prolongs the network lifetime. E-CARP consists of two phases, namely network initialization and control and data packet forwarding. In the network initialization phase, a hello packet is broadcasted from sink node throughout the whole network area. Each of the sensor nodes will have a unique source id and hop count which represents the distance to the sink node. The farthest distance from the sink node will have the biggest hop count. When the network has been initialized, the topology is established and each sensor node is aware of its distance to SN.

During data packet forwarding, when a source node has data packet to send, it will broadcast a control message to neighbours node within the communication range. Different from CARP, not all neighbours node will reply the message, and the nodes reply only one or very few based on the relay node selection mechanism. This strategy ensures a less control packet is used during the steady network topology.

E-CARP protocol is advantageous as it adopts the location free principle while hop counts are used as heuristics to guide packet forwarding to the sink nodes. However there are still some weaknesses in E-CARP, such as the hop count will remarkably increase in dense networks with many sensor nodes, which can cause an increase in energy consumption. Although communication void is a critical problem in OR, this protocol does not consider this problem.

\section{Comparison Study}

As stated earlier, OR is the most favorable routing method in UWSNs due to the unique characteristics of underwater environments and dynamic topology network in UWSNs. However, this approach suffers from a high network traffic through the duplicated packet transmission and high energy consumption from that. Therefore, most of the existing proposed energy efficient OR protocols are to overcome the redundant packet transmission by reducing the retransmission or redundant packets. OR protocols can be divided into 3 categories which are SSB, RSB and Hybrid.

In Table 1, we make a comparison between these 3 categories of energy efficient OR protocols. Each of this category has their own advantage and disadvantage where no one category is superior to the other. SSB is more suitable in dense distribution because it can handle many nodes efficiently while RSB is better in sparse distribution. Hybrid category is more towards the overall network performance with minimal overhead. However, in terms of energy efficiency each category shows that each of the protocols belonging to them uses different method but has the same objectives to minimize traffic load, reduce energy consumption to prolong the network lifetime and have good reliability in terms of data delivery.

Table 2 reveals an overview of energy efficient OR protocol performance (Energy Consumption, End-to-End Delay and Packet Delivery Ratio) based on their simulation results. From the table, it shows that the sender based routing protocol is superior in dense deployment, while for receiver based routing protocols, their overall performance is not really good. This is because, in dense situation, for receiver based approach, many nodes can take part in forwarding the packet which could lead more energy consumption and also network congestion. Based on this table, the sender based routing protocol is better solution, however the sender based approach also had problem in sparse deployment. There are some possiblities that sender based approach does not have good performance because lack of candidate for forwarding. 
Table 3 is the summary for all of the multi-criteria routing protocols for candidate selection set and ranking nodes. Most of the existing proposed routing are using the residual energy, distance, link quality and depth for their criterion for candidate selection set and ranking. However, the main problem for current existing proposed solution is no priority on selection for criteria to be used and some of them are using complex solution like PER and EEF.

Table 4 shows the simulation parameter that is being used by the protocols to show their performance against other protocols. There are several types of simulators that are being used by researchers to perform simulation and emulate their protocols in underwater environment. However, currently there is no such standard parameter for underwater simulation, even the characteristics of underwater are also being assumed differently among the researcher.

Table 1. Comparison of energy efficient OR protocols.

\begin{tabular}{|c|c|c|}
\hline Category & Advantage & Disadvantage \\
\hline $\begin{array}{c}\text { Sender Side } \\
\text { Based }\end{array}$ & $\begin{array}{c}\text { Routing protocols can be } \\
\text { robust and would efficiently } \\
\text { respond to the impairment in } \\
\text { the acoustic channel of } \\
\text { communication. Suitable for } \\
\text { dense networks deployment. }\end{array}$ & $\begin{array}{c}\text { Very high end-to-end delay } \\
\text { and high packet overhead in } \\
\text { network communication. } \\
\text { Poor performance in dense } \\
\text { network deployment. }\end{array}$ \\
\hline Receiver & $\begin{array}{c}\text { Routing protocol is simple and } \\
\text { scalable while very suitable for } \\
\text { sparse network deployment } \\
\text { and very attractive for high } \\
\text { mobility scenarios. }\end{array}$ & $\begin{array}{c}\text { Highly redundant packet } \\
\text { would occur in the network } \\
\text { because of hidden terminal } \\
\text { problem which is one of the } \\
\text { issues in OR. }\end{array}$ \\
\hline Hybrid & $\begin{array}{c}\text { Main advantage for this } \\
\text { approach is OR protocol can } \\
\text { be designed with minimal } \\
\text { packet overhead which can } \\
\text { improve significantly network } \\
\text { performance }\end{array}$ & $\begin{array}{c}\text { Very high end-to-end delay } \\
\text { would occur when there are } \\
\text { too many nodes to be chosen } \\
\text { as the forwarder. }\end{array}$ \\
\hline
\end{tabular}

Table 2. Performance evaluation for energy efficient OR protocols in UWSNs.

\begin{tabular}{|c|c|c|c|c|c|}
\hline \multirow{2}{*}{ Category } & Protocol & \multicolumn{4}{|c|}{ Performance Evaluation } \\
\cline { 3 - 6 } & $\begin{array}{c}\text { Energy } \\
\text { Consumption }\end{array}$ & $\begin{array}{c}\text { End-to-End } \\
\text { Delay }\end{array}$ & $\begin{array}{c}\text { Packet } \\
\text { Delivery } \\
\text { Ratio }\end{array}$ & $\begin{array}{c}\text { Dense } \\
\text { Network }\end{array}$ \\
\hline \multirow{2}{*}{$\begin{array}{c}\text { Sender } \\
\text { Side Based }\end{array}$} & SEANAR[40] & Low & NA & Medium & Medium \\
\cline { 2 - 6 } & PER[41] & Medium & Medium & Medium & Medium \\
\hline
\end{tabular}


Nasarudin Ismail et al.: REVIEW ON ENERGY EFFICIENT OPPORTUNISTIC ROUTING PROTOCOL FOR UNDERWATER WIRELESS SENSOR NETWORKS

\begin{tabular}{|c|c|c|c|c|c|}
\hline & DREE[34] & Medium & Low & High & Good \\
\hline & EEDBR[43] & Medium & Low & High & Good \\
\hline & R-ERP2R[35] & Medium & Low & High & Good \\
\hline & GEDAR[42] & Medium & Low & High & Good \\
\hline & $\mathrm{DRP}[45]$ & Medium & Low & High & Good \\
\hline & EnOR[46] & Medium & Low & High & Medium \\
\hline & Co-UWSN [47] & Medium & Low & High & Good \\
\hline & RE-PBR[44] & Medium & Low & High & Medium \\
\hline \multirow{10}{*}{$\begin{array}{c}\text { Receiver } \\
\text { Side Based }\end{array}$} & VBF[37] & High & High & Medium & Poor \\
\hline & HH-VBF[48] & High & Medium & High & Medium \\
\hline & DBR[38] & High & High & Medium & Poor \\
\hline & AHH-VBF[49] & Low & Low & Medium & Medium \\
\hline & $\mathrm{EEF}[50]$ & Medium & Medium & Medium & Medium \\
\hline & iAMCTD[39] & Low & Low & High & Medium \\
\hline & WDFAD-DBR[36] & Low & High & High & Good \\
\hline & HydroCast[33] & Medium & Medium & High & Medium \\
\hline & BMOOR[52] & Medium & Low & High & Medium \\
\hline & DUOR[53] & High & High & Medium & Poor \\
\hline
\end{tabular}




\begin{tabular}{|c|c|c|c|c|c|}
\hline & ERP2R[51] & Medium & Low & High & Medium \\
\hline \multirow{3}{*}{ Hybrid } & FBR[54] & Medium & Medium & NA & Medium \\
\cline { 2 - 6 } & E-CARP[55] & Medium & Medium & High & Good \\
\hline
\end{tabular}

Table 3. Summary of multi-criteria approach Energy Efficient Routing Protocols for UWSNs

\begin{tabular}{|l|c|l|l|l|}
\hline Protocol & $\begin{array}{l}\text { Number } \\
\text { of } \\
\text { Criteria }\end{array}$ & Criteria & Calculation & $\begin{array}{l}\text { Drawback for } \\
\text { calculation }\end{array}$ \\
\hline $\begin{array}{l}\text { SEANAR } \\
\text { [40] }\end{array}$ & 3 & $\begin{array}{l}\text { Distance to sink, } \\
\text { residual energy } \\
\text { and inner and } \\
\text { aside degree }\end{array}$ & Weightage & $\begin{array}{l}\text { No mention } \\
\text { priority criteria } \\
\text { on calculation }\end{array}$ \\
\hline $\begin{array}{l}\text { Co-UWSN } \\
\text { [47] }\end{array}$ & 3 & $\begin{array}{l}\text { SNR, Residual } \\
\text { Energy and } \\
\text { Distance }\end{array}$ & Weightage & $\begin{array}{l}\text { No mention } \\
\text { priority criteria } \\
\text { on calculation }\end{array}$ \\
\hline EEF [50] & 3 & $\begin{array}{l}\text { Depth, residual } \\
\text { energy and } \\
\text { distance }\end{array}$ & $\begin{array}{l}\text { Fitness } \\
\text { value }\end{array}$ & $\begin{array}{l}\text { No mention } \\
\text { priority criteria } \\
\text { on calculation }\end{array}$ \\
\hline PER [41] & 3 & $\begin{array}{l}\text { Distance, residual } \\
\text { energy, and angle } \\
\text { between two } \\
\text { neighbours }\end{array}$ & $\begin{array}{l}\text { Fuzzy logic } \\
\text { system }\end{array}$ & $\begin{array}{l}\text { Very complex } \\
\text { calculation }\end{array}$ \\
\hline $\begin{array}{l}\text { R-ERP2R } \\
\text { [35] }\end{array}$ & 2 & $\begin{array}{l}\text { ETX and Residual } \\
\text { Energy }\end{array}$ & Route cost & $\begin{array}{l}\text { No mention } \\
\text { priority criteria } \\
\text { on calculation }\end{array}$ \\
\hline DREE [34] & 2 & $\begin{array}{l}\text { Distance and Link } \\
\text { Quality }\end{array}$ & $\begin{array}{l}\text { Route Cost } \\
\text { and residual } \\
\text { energy }\end{array}$ & $\begin{array}{l}\text { No mention } \\
\text { priority criteria } \\
\text { on calculation }\end{array}$ \\
\hline iAMCTD \\
[39]
\end{tabular}


Table 4. Simulation Parameters for Energy Efficient OR Protocol in UWSNs

\begin{tabular}{|c|c|c|c|c|c|c|c|c|c|c|c|c|c|}
\hline \multirow{2}{*}{ : } & \multirow{2}{*}{ 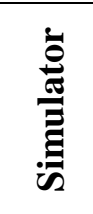 } & \multirow{2}{*}{ 氮 } & \multirow{2}{*}{ 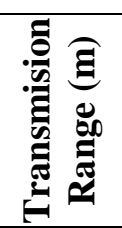 } & \multirow{2}{*}{ 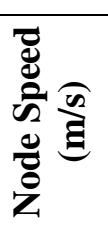 } & \multirow{2}{*}{ 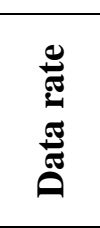 } & \multirow{2}{*}{ 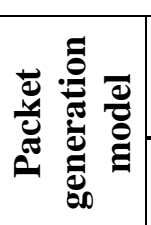 } & \multicolumn{4}{|c|}{ Energy Tax } & \multirow{2}{*}{ 总 } & \multirow{2}{*}{ 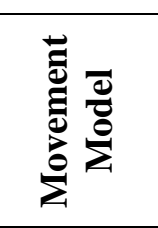 } & \multirow{2}{*}{ 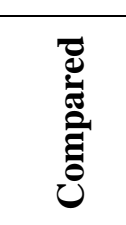 } \\
\hline & & & & & & & Initial & Send & Rec. & $\begin{array}{c}\text { Idl } \\
\text { e }\end{array}$ & & & \\
\hline $\begin{array}{c}\text { SEANA } \\
\text { R[40] }\end{array}$ & $\mathrm{C}++$ & $\begin{array}{c}240 \mathrm{x} \\
240 \mathrm{x} \\
240 \mathrm{~m}^{3}\end{array}$ & $30 \mathrm{~m}$ & $\begin{array}{l}0.2 \\
\mathrm{~m} / \mathrm{s}\end{array}$ & NA & NA & $1000 \mathrm{~J}$ & $\begin{array}{l}60 \mu \mathrm{J} \\
/ \mathrm{bit}\end{array}$ & $\begin{array}{c}3 \mu \mathrm{J} / \\
\text { bit }\end{array}$ & NA & Single & $\begin{array}{l}\text { Random } \\
\text { Mobility }\end{array}$ & $\begin{array}{c}\text { GF,VB } \\
\text { F }\end{array}$ \\
\hline PER[41] & $\mathrm{C}++$ & $\begin{array}{c}500 x \\
500 x \\
500 \mathrm{~m}^{3}\end{array}$ & $100 \mathrm{~m}$ & $\begin{array}{c}1-5 \\
\mathrm{~m} / \mathrm{s}\end{array}$ & $\begin{array}{c}4 \\
\text { kbps }\end{array}$ & NA & NA & NA & NA & NA & Single & $\begin{array}{c}\text { Random } \\
\text { Walk } \\
\text { 2D } \\
\text { mobility } \\
\end{array}$ & DBR \\
\hline $\begin{array}{c}\text { DREE } \\
{[34]}\end{array}$ & NS2 & $\begin{array}{c}900 \mathrm{x} \\
900 \mathrm{x} \\
900 \mathrm{~m}^{3}\end{array}$ & $200 \mathrm{~m}$ & $2 \mathrm{~m} / \mathrm{s}$ & NA & $\begin{array}{c}50 \\
\text { bytes } \\
\text { every } \\
15 \mathrm{~s}\end{array}$ & $100 \mathrm{~J}$ & $2 \mathrm{~W}$ & $0.1 \mathrm{~W}$ & $\begin{array}{l}10 \\
\mathrm{~m} \\
\mathrm{~W}\end{array}$ & $\begin{array}{l}\text { Multi } \\
\text { (fixed) }\end{array}$ & $\begin{array}{l}\text { Random } \\
\text { Mobility }\end{array}$ & $\begin{array}{c}\text { DBR,R } \\
- \\
\text { ERP }^{2} R\end{array}$ \\
\hline $\begin{array}{c}\text { EEDBR } \\
{[43]}\end{array}$ & NS2 & NA & $250 \mathrm{~m}$ & NA & NA & $\begin{array}{c}64 \\
\text { bytes } \\
\text { every } \\
15 s\end{array}$ & $70 \mathrm{~J}$ & NA & NA & NA & $\begin{array}{l}\text { Multi } \\
\text { (fixed) }\end{array}$ & $\begin{array}{l}\text { Random } \\
\text { Mobility }\end{array}$ & DBR \\
\hline $\begin{array}{c}\mathrm{R}- \\
\mathrm{ERP}^{2} \mathrm{R} \\
{[35]}\end{array}$ & NS2 & NA & $250 \mathrm{~m}$ & NA & NA & $\begin{array}{c}1 \\
\text { packet } \\
\text { every } \\
15 \mathrm{~s}\end{array}$ & $70 \mathrm{~J}$ & NA & NA & NA & $\begin{array}{l}\text { Multi } \\
\text { (fixed) }\end{array}$ & $\begin{array}{l}\text { Random } \\
\text { Mobility }\end{array}$ & $\begin{array}{l}\text { DBR, } \\
\text { ERP }^{2} R\end{array}$ \\
\hline $\begin{array}{c}\text { RE-PBR } \\
{[44]}\end{array}$ & NS2 & $\begin{array}{c}1250 \mathrm{~m} \\
\mathrm{x} \\
1250 \mathrm{~m} \\
\mathrm{X} \\
1250 \mathrm{~m} \\
\end{array}$ & $250 \mathrm{~m}$ & $\begin{array}{c}0- \\
3 \mathrm{~m} / \mathrm{s}\end{array}$ & $\begin{array}{c}10 \\
\text { kbps }\end{array}$ & $\begin{array}{l}1 \text { per } \\
15 \mathrm{~s}\end{array}$ & $100 \mathrm{~J}$ & $2 \mathrm{~W}$ & $\begin{array}{c}0.75 \\
W\end{array}$ & $\begin{array}{l}8 \\
\mathrm{~m} \\
\mathrm{~W}\end{array}$ & Multi & $\begin{array}{l}\text { Random } \\
\text { Mobility } \\
\text { and Grid }\end{array}$ & $\begin{array}{c}\text { DBR, } \\
\text { EEDB } \\
\text { R }\end{array}$ \\
\hline DRP[45] & NS2 & $\begin{array}{c}2000 \mathrm{~m} \\
\mathrm{x} \\
2000 \mathrm{~m} \\
\mathrm{x} \\
2000 \mathrm{~m}\end{array}$ & $1000 \mathrm{~m}$ & $\begin{array}{l}0.3 \\
\mathrm{~m} / \mathrm{s}\end{array}$ & $\begin{array}{c}5 \\
\text { kbps }\end{array}$ & $\begin{array}{c}0.4 \\
\mathrm{pkt} / \mathrm{s}\end{array}$ & NA & $10 \mathrm{~W}$ & $\begin{array}{l}300 \\
\mathrm{~mW}\end{array}$ & $\begin{array}{l}80 \\
\mathrm{~m} \\
\mathrm{~W}\end{array}$ & Single & $\begin{array}{l}\text { Random } \\
\text { Mobility }\end{array}$ & $\begin{array}{l}\text { EEDB, } \\
\text { ERP }^{2} \mathrm{R}, \\
\mathrm{RERP}^{2} \\
\mathrm{R}\end{array}$ \\
\hline $\begin{array}{c}\text { EnOR[4 } \\
6]\end{array}$ & NS2 & $\begin{array}{c}1000 \mathrm{~m} \\
\mathrm{x} \\
1000 \mathrm{~m} \\
\mathrm{x} \\
1000 \mathrm{~m}\end{array}$ & $250 \mathrm{~m}$ & NA & $\begin{array}{l}20 \\
\text { kbps }\end{array}$ & $\begin{array}{c}0.01 \\
\mathrm{pkts} / \mathrm{m} \\
\text { in }\end{array}$ & NA & $4 \mathrm{~W}$ & $\begin{array}{c}0.65 \\
W\end{array}$ & NA & $\begin{array}{l}\text { Multi } \\
\text { (Fixed } \\
\text { ) }\end{array}$ & $\begin{array}{l}\text { Random } \\
\text { Mobility }\end{array}$ & $\begin{array}{l}\text { DBR, } \\
\text { VAPR }\end{array}$ \\
\hline $\begin{array}{c}\text { Co- } \\
\text { UWSN } \\
{[47]}\end{array}$ & NA & $\begin{array}{c}500 \mathrm{~m} \mathrm{x} \\
500 \mathrm{~m}\end{array}$ & NA & NA & NA & NA & NA & NA & NA & NA & Multi & $\begin{array}{l}\text { Random } \\
\text { Mobility }\end{array}$ & $\begin{array}{l}\text { EEDB } \\
\text { R, } \\
\text { iAMC } \\
\text { TD }\end{array}$ \\
\hline $\begin{array}{c}\text { GEDAR } \\
\text { [42] }\end{array}$ & NS2 & $\begin{array}{c}1500 \mathrm{~m} \\
\mathrm{x} \\
1500 \mathrm{~m}\end{array}$ & $250 \mathrm{~m}$ & $\begin{array}{c}0.3 \mathrm{~m} \\
/ \mathrm{s}\end{array}$ & $\begin{array}{c}50 \\
\text { kbps }\end{array}$ & $\begin{array}{c}0.3 \\
\mathrm{pkt} / \mathrm{mi} \\
\mathrm{n}\end{array}$ & NA & $2 \mathrm{~W}$ & $0.1 \mathrm{~W}$ & $\begin{array}{l}10 \\
\mathrm{~m} \\
\mathrm{~W}\end{array}$ & $\begin{array}{c}\text { Multi } \\
\text { (fixed) }\end{array}$ & $\begin{array}{l}\text { Meande } \\
\text { ring } \\
\text { Current }\end{array}$ & $\begin{array}{l}\text { VAPR, } \\
\text { DBR }\end{array}$ \\
\hline
\end{tabular}




\begin{tabular}{|c|c|c|c|c|c|c|c|c|c|c|c|c|c|c|}
\hline & & $\begin{array}{c}\mathrm{x} \\
1500 \mathrm{~m}\end{array}$ & & & & & & & & & & & $\begin{array}{c}\text { Mobility } \\
\text { (MCM) } \\
\text { [20] }\end{array}$ & \\
\hline VBF[37] & NA & $\begin{array}{c}100 \mathrm{x} \\
100 \mathrm{x} \\
100 \mathrm{~m}^{3}\end{array}$ & & $20 \mathrm{~m}$ & $\begin{array}{l}0-5 \\
\mathrm{~m} / \mathrm{s}\end{array}$ & NA & $\begin{array}{c}2 \\
\text { packet } \\
\text { s per } \\
\text { second } \\
\end{array}$ & NA & NA & NA & NA & $\begin{array}{l}\text { Single } \\
\text { (fixed) }\end{array}$ & Uniform & NA \\
\hline $\begin{array}{c}\mathrm{HH}- \\
\text { VBF[48] }\end{array}$ & NS2 & $\begin{array}{l}1000 \mathrm{x} \\
1000 \mathrm{x} \\
500 \mathrm{~m}^{3}\end{array}$ & & $00 \mathrm{~m}$ & NA & $\begin{array}{c}10 \\
\text { kbps }\end{array}$ & $\begin{array}{c}1 \\
\text { packet } \\
\text { per } \\
10 \mathrm{~s} \\
\end{array}$ & NA & $2 \mathrm{~W}$ & $\begin{array}{c}0.75 \\
W\end{array}$ & $\begin{array}{l}8 \\
\mathrm{~m} \\
\mathrm{~W}\end{array}$ & $\begin{array}{l}\text { Single } \\
\text { (fixed) }\end{array}$ & $\begin{array}{l}\text { Random } \\
\text { Mobility }\end{array}$ & VBF \\
\hline DBR[38] & NS2 & $\begin{array}{c}500 \mathrm{x} \\
500 \mathrm{x} \\
500 \mathrm{~m}^{3}\end{array}$ & & $.00 \mathrm{~m}$ & $\begin{array}{c}1-5 \\
\mathrm{~m} / \mathrm{s}\end{array}$ & $\begin{array}{c}10 \\
\text { kbps }\end{array}$ & $\begin{array}{c}1 \\
\text { packet } \\
\text { per } \\
\text { second } \\
\end{array}$ & NA & $2 \mathrm{~W}$ & $0.1 \mathrm{~W}$ & $\begin{array}{l}10 \\
\mathrm{~m} \\
\mathrm{~W}\end{array}$ & $\begin{array}{l}\text { Multi } \\
\text { (fixed) }\end{array}$ & $\begin{array}{c}\text { Random } \\
\text { Walk } \\
\text { 2D } \\
\text { mobility }\end{array}$ & VBF \\
\hline $\begin{array}{c}\text { AHH- } \\
\text { VBF[49] }\end{array}$ & NS3 & $\begin{array}{c}10000 \mathrm{x} \\
10000 \mathrm{x} \\
10000 \\
\mathrm{~m}^{3} \\
\end{array}$ & & $000 \mathrm{~m}$ & $3 \mathrm{~m} / \mathrm{s}$ & $\begin{array}{c}16 \\
\text { Kbps }\end{array}$ & $\begin{array}{c}1 \\
\text { packet } \\
\text { per } 5 \mathrm{~s}\end{array}$ & NA & $\begin{array}{c}90 \\
\mathrm{~dB} \\
\mathrm{re \mu} P \\
\mathrm{a} \\
\end{array}$ & $\begin{array}{c}10 \\
\mathrm{~dB} \\
\mathrm{re} \mu \mathrm{P} \\
\mathrm{a} \\
\end{array}$ & NA & Single & $\begin{array}{c}\text { Random } \\
\text { Walk } \\
\text { 2D } \\
\text { mobility }\end{array}$ & $\begin{array}{l}\text { VBF,H } \\
\text { H-VBF }\end{array}$ \\
\hline $\mathrm{EEF}[50]$ & NS2 & $\begin{array}{c}500 \mathrm{x} \\
500 \mathrm{x} \\
500 \mathrm{~m}^{3}\end{array}$ & & $00 \mathrm{~m}$ & $\begin{array}{l}1-10 \\
\mathrm{~m} / \mathrm{s}\end{array}$ & $\begin{array}{c}10 \\
\text { kbps }\end{array}$ & $\begin{array}{c}2 \\
\text { packet } \\
\text { s per } \\
\text { second }\end{array}$ & $80 \mathrm{~J}$ & $3 \mathrm{~W}$ & $3 \mathrm{~W}$ & $3 \mathrm{~W}$ & $\begin{array}{l}\text { Multi } \\
\text { (fixed) }\end{array}$ & $\begin{array}{l}\text { Random } \\
\text { Mobility }\end{array}$ & DBR \\
\hline $\begin{array}{c}\text { iAMCT } \\
\text { D [39] }\end{array}$ & $\begin{array}{c}\text { Exte } \\
\text { nsive } \\
\text { Simu } \\
\text { latio } \\
\mathrm{n} \\
\end{array}$ & NA & & $.00 \mathrm{~m}$ & NA & $\begin{array}{c}10 \\
\text { kbps }\end{array}$ & NA & $70 \mathrm{~J}$ & $2 \mathrm{~W}$ & $0.1 \mathrm{~W}$ & $\begin{array}{l}10 \\
\mathrm{~m} \\
\mathrm{~W}\end{array}$ & Multi & $\begin{array}{l}\text { Random } \\
\text { Mobility }\end{array}$ & $\begin{array}{c}\text { AMCT } \\
\text { D,EED } \\
\text { BR, } \\
\text { DBR }\end{array}$ \\
\hline $\begin{array}{c}\text { WDFAD } \\
- \\
\text { DBR[36] }\end{array}$ & NS-3 & $\begin{array}{c}10000 \mathrm{x} \\
10000 \mathrm{x} \\
10000 \\
\mathrm{~m}^{3}\end{array}$ & & $000 \mathrm{~m}$ & $2 \mathrm{~m} / \mathrm{s}$ & $\begin{array}{c}16 \\
\text { kbps }\end{array}$ & $\begin{array}{c}1 \text { per } \\
5 \mathrm{~s}\end{array}$ & NA & $50 \mathrm{~W}$ & $\begin{array}{l}158 \\
\mathrm{~mW}\end{array}$ & $\begin{array}{c}158 \\
\mathrm{~m} \\
\mathrm{~W}\end{array}$ & $\begin{array}{l}\text { Multi } \\
\text { (fixed) }\end{array}$ & $\begin{array}{c}\text { Random } \\
\text { Walk } \\
\text { 2D } \\
\text { mobility } \\
\text { model }\end{array}$ & $\begin{array}{l}\text { Floodin } \\
\text { g, DBR }\end{array}$ \\
\hline $\begin{array}{l}\text { HydroCa } \\
\text { st[33] }\end{array}$ & $\begin{array}{l}\text { Qual } \\
\text { net }\end{array}$ & $\begin{array}{c}1000 \mathrm{x} \\
1000 \mathrm{x} \\
1000 \mathrm{~m}^{3}\end{array}$ & & $50 \mathrm{~m}$ & $\begin{array}{l}0.3 \\
\mathrm{~m} / \mathrm{s}\end{array}$ & $\begin{array}{c}50 \\
\text { kbps }\end{array}$ & $\begin{array}{c}1 \text { per } \\
60 \mathrm{~s}\end{array}$ & NA & $\begin{array}{c}105 \\
\mathrm{~dB} \\
\mathrm{re \mu} P \\
\mathrm{a} \\
\end{array}$ & NA & NA & Multi & $\begin{array}{l}\text { Random } \\
\text { /Passive } \\
\text { Mobility }\end{array}$ & DBR \\
\hline $\begin{array}{c}\text { BMOOR } \\
{[52]}\end{array}$ & NS2 & $\begin{array}{c}300 \mathrm{mx} \\
300 \mathrm{~m} \mathrm{x} \\
300 \mathrm{~m}\end{array}$ & & $.00 \mathrm{~m}$ & NA & $\begin{array}{c}64 \\
\text { bytes }\end{array}$ & $\begin{array}{c}1 \text { per } \\
30 \mathrm{~s}\end{array}$ & $70 \mathrm{~J}$ & $2 \mathrm{~W}$ & $\begin{array}{c}0.75 \\
W\end{array}$ & $\begin{array}{l}8 \mathrm{~m} \\
\mathrm{~W}\end{array}$ & Single & $\begin{array}{l}\text { Random } \\
\text { Mobilty }\end{array}$ & $\begin{array}{c}\text { DBR, } \\
\text { EEDB } \\
\text { R, } \\
\text { MRP }\end{array}$ \\
\hline $\begin{array}{c}\text { DUOR } \\
\text { [53] }\end{array}$ & $\begin{array}{c}\text { OPNE } \\
\mathrm{T}\end{array}$ & $\begin{array}{c}500 \mathrm{~m} \\
\mathrm{x} \\
500 \mathrm{~m} \\
\mathrm{x} \\
500 \mathrm{~m} \\
\end{array}$ & $\begin{array}{l}100 \\
\mathrm{~m}\end{array}$ & $\begin{array}{c}\text { Spheri } \\
\text { cal }\end{array}$ & $\begin{array}{l}0-5 \\
\mathrm{~m} / \mathrm{s}\end{array}$ & $\begin{array}{c}10 \\
\text { kbps }\end{array}$ & 1 per $1 \mathrm{~s}$ & $400 \mathrm{~J}$ & $2 \mathrm{~W}$ & $0.75 \mathrm{~W}$ & $\begin{array}{c}8 \\
\mathrm{~mW}\end{array}$ & Single & $\begin{array}{l}\text { Random } \\
\text { Mobility }\end{array}$ & DBR \\
\hline
\end{tabular}




\begin{tabular}{|c|c|c|c|c|c|c|c|c|c|c|c|c|c|}
\hline $\begin{array}{c}\text { ERP2R } \\
\text { [51] }\end{array}$ & NS2 & NA & $\begin{array}{c}250 \\
\mathrm{~m}\end{array}$ & NA & NA & 1 per $15 \mathrm{~s}$ & $70 \mathrm{~J}$ & NA & NA & NA & $\begin{array}{c}\text { Multi } \\
\text { (fixed) }\end{array}$ & $\begin{array}{l}\text { Random } \\
\text { Mobility }\end{array}$ & DBR \\
\hline $\begin{array}{l}\text { FBR } \\
{[54]}\end{array}$ & $\begin{array}{c}\text { Pytho } \\
\text { n }\end{array}$ & $\begin{array}{c}20000 \\
0 \mathrm{x} \\
20000 \\
\mathrm{~m}^{2}\end{array}$ & NA & NA & NA & $\begin{array}{c}\lambda \text { in } \\
\text { packets/s } \\
\text { econd }\end{array}$ & NA & NA & NA & NA & $\begin{array}{c}\text { Multi } \\
\text { (fixed) }\end{array}$ & $\begin{array}{l}\text { Random } \\
\text { Mobility }\end{array}$ & NA \\
\hline $\begin{array}{c}\text { E-CARP } \\
\text { [55] }\end{array}$ & Java & $\begin{array}{c}1000 \\
x \\
2000 \\
x 240 \\
m^{3}\end{array}$ & $\begin{array}{c}250 \\
\mathrm{~m}\end{array}$ & NA & $\begin{array}{c}100,5 \\
12,10 \\
00 \\
\text { bytes }\end{array}$ & $\begin{array}{c}1500 \\
\text { packet } \\
\text { per } \\
\text { round }\end{array}$ & NA & $\begin{array}{c}2.8 \mathrm{w} \\
\text { Data, } \\
1.5 \mathrm{w} \\
\text { control }\end{array}$ & NA & NA & Single & $\begin{array}{l}\text { Random } \\
\text { Mobility }\end{array}$ & CARP \\
\hline
\end{tabular}

\section{Future Works and Conclusion}

There are undoubtedly benefits of using OR in UWSNs that have suffered from limited bandwidth, link inefficiency and higher energy consumption. However, there are still many open issues that deserve a greater attention in order to achieve a better network performance in UWSNs with the use of OR protocols especially in terms of energy efficient.

\subsection{Future Works}

1. Optimal selection of the next hop forwarder candidate should be designed in balancing between the performance and reliability of the network. It is clear that if there are too many candidates for the next hop forwarder there would be greater chances for the packets to have higher percentages of delivery success towards the destination, but at the same time there would be a chance of duplicated transmission, which could incur extra energy cost and bandwidth. In order to avoid this, there are chances for future researches on the effects of suitable number of candidates for the next hop forwarder with the performance of UWSNs.

2. Communication void is one of the major issues in UWSNs especially for OR protocol which can translate to poor performance of networks. Currently many existing proposed communication void algorithm for UWSNs is using flooding technique to find a detour path. Therefore, there are chances for future researches to design a better technique while still maintaining the low overhead in UWSNs.

3. Many of the proposed routing protocols in UWSNs are having good perfomance in sparse networks deployment while in dense networks, their performance are poor in terms of energy consumption, end-to-end delay and packet delivery ratio. Therefore, there are chances for future researches to design a routing protocol which can have the best performance in both conditions either in sparse or dense networks deployment.

4. Secure communication between sensor nodes is one of the main challenges in many UWSNs applications especially for millitary purposes. However, the existing proposed routing protocols do not take any action regarding this issue. Therefore, designing a secure routing protocol for UWSNs is still a great challenge in the future.

5. As of now, there is no standard simulation/emulator to cater for all characteristics of UWSNs like acoustic communication, propagation delay, 3d deployment etc. Most popular network simulators such as QualNet, OPNET, Aqua-Glomo, SUNSET, NS2 and NS3 cannot effectively reproduce the actual underwater environment in their simulation tools[56]. Therefore, there is still a need for developing standard and efficient simulator for UWSNs to 
cater for all the features and limitations in underwater environments.

\subsection{Conclusion}

This research article focuses on energy efficient OR protocols for UWSNs. In this paper we provide a comprehensive survey of various energy efficient OR protocols in UWSNs. We classify the energy efficient OR based on the characteristic of protocol into 3 categories, which are sender-side-based, receiver-side-based and hybrid-based. We provide in-depth explanation for all the protocols with their advantages and disadvantages. Moreover, we also give some comparisons between each category on its advantages and disadvantages. The limitation of existing proposed routing protocols will guide the researchers to further research in the field of routing protocols for UWSNs especially by using OR approach in routing protocol for UWSNs.

\section{Acknowledgement}

This paper has been sponsored by using UTM Research University Grant (Title: The prototype of wearable wireless sensing for specific human motions disorder Vot No: Q.J130000.2507.18H54

\section{References}

[1] I.F. Akyildiz, D. Pompili, T. Melodia, "Underwater acoustic sensor networks: Research challenges,” Ad Hoc Networks, Vol. 3, pp. 257-279, 2005. Article (CrossRef Link)

[2] M. Ayaz, I. Baig, A. Abdullah, I. Faye, "A survey on routing techniques in underwater wireless sensor networks,” J. Netw. Comput, Appl. Vol. 34, pp. 1908-1927, 2011. Article (CrossRef Link)

[3] J. Heidemann, Wei Ye, J. Wills, A. Syed, Yuan Li, "Research challenges and applications for underwater sensor networking," in Proc. of IEEE Wirel. Commun. Netw. Conf. 2006. WCNC 2006. 0, pp. 228-235, 2006. Article (CrossRef Link)

[4] P. Casari, M. Zorzi, "Protocol design issues in underwater acoustic networks," Comput. Commun., vol. 34, pp. 2013-2025,2011. Article (CrossRef Link)

[5] A. Khasawneh, A. Khasawneh, M. Shafie, B. Abd, O. Kaiwartya, Next Forwarding Node Selection in Underwater Wireless Sensor Networks ( UWSNs ): Techniques and Challenges Next Forwarding Node Selection in Underwater Wireless Sensor Networks ( UWSNs ): Techniques and Challenges, Information. 8, 3,2016. Article (CrossRef Link)

[6] M. Ayaz, A. Abdullah, "Underwater wireless sensor networks," in Proc. of 7th Int. Conf. Adv. Mob. Comput. Multimed. - MoMM '09., 370, 2009. Article (CrossRef Link)

[7] D. Pompili, T. Melodia, I. Akyildiz, "A resilient routing algorithm for long-term applications in underwater sensor networks,” in Proc. of Med-Hoc-Net'06, 2006. Article (CrossRef Link)

[8] M.C. Domingo, R. Prior, "Energy analysis of routing protocols for underwater wireless sensor networks,” Comput. Commun, vol. 31, pp. 1227-1238, 2008. Article (CrossRef Link)

[9] D. Pompili, I.F. Akyildiz, "Overview of Networking Protocols for Underwater Wireless Communications,” IEEE Commun. Mag., vol. 47, pp. 97-102, 2009. Article (CrossRef Link)

[10] M.T. Kheirabadi, M.M. Mohamad, "Greedy Routing in Underwater Acoustic Sensor Networks : A Survey,” Int. J. Distrib. Sens. Networks. 2013, 21, 2013. Article (CrossRef Link).

[11] I.F. Akyildiz, D. Pompili, T. Melodia, "State-of-the-art in protocol research for underwater acoustic sensor networks," in Proc. of 1st ACM Int. Work. Underw. Networks - WUWNet '06., 7, 2006.Article (CrossRef Link) 
[12] G. Han, N. Bao, L. Liu, D. Zhang, L. Shu, "Routing Protocols in Underwater Acoustic Sensor Networks: A Quantitative Comparison,” Int. J. Distrib. Sens. Networks., pp. 1-11, 2015. Article (CrossRef Link)

[13] N. Hemavathy, M. Mugesh, P. Indumathi, "The Performance of Different Routing Protocols Available in Underwater Wireless Sensor Network-A Survey,” pp. 527-531, 2016.

[14] M. Ahmed, M. Salleh, M.I. Channa, "Routing protocols based on node mobility for Underwater Wireless Sensor Network (UWSN): A survey,” J. Netw. Comput. Appl., pp. 1-11, 2016. Article (CrossRef Link)

[15] N. Li, J.-F. Martínez, J. Meneses Chaus, M. Eckert, “A Survey on Underwater Acoustic Sensor Network Routing Protocols,” Sensors., vol. 16, pp. 414, 2016. Article (CrossRef Link)

[16] A. Khasawneh, U. Teknologi, A. Latiff, M. Shafie, U. Teknologi, H. Chizari, U. Teknologi, A. Bamatraf, U. Teknologi, F. Flood, D. Using, D. Radio, S. Network, U.A. View, A. Khasawneh, "Pressure Based Routing Protocol for Underwater Wireless Sensor Network: A Survey,” KSII Trans. Internet Inf. Syst., vol. 9,pp. 504-527, 2015. Article (CrossRef Link)

[17] V.G. Menon, P.M.J. Prathap, "Comparative analysis of opportunistic routing protocols for underwater acoustic sensor networks,” in Proc. of 2016 Int. Conf. Emerg. Technol. Trends, IEEE, pp. 1-5, 2016. Article (CrossRef Link)

[18] S.M. Ghoreyshi, A. Shahrabi, T. Boutaleb, "Void-Handling Techniques for Routing Protocols in Underwater Sensor Networks : Survey and Challenges,” pp. 1-28, 2017. Article (CrossRef Link)

[19] M. Ahmed, M. Salleh, M.I. Channa, "Routing protocols based on node mobility for Underwater Wireless Sensor Network (UWSN): A survey,” J. Netw. Comput. Appl., vol. 78, pp. 242-252, 2017. Article (CrossRef Link)

[20] C. Giantsis, A.A. Economides, "Comparison of Routing Protocols for Underwater Sensor Networks: A Survey,” Int. J. Commun. Networks Distrib. Syst., vol. 7, pp. 192-228, 2011. Article (CrossRef Link)

[21] K. Ovaliadis, N. Savage, V. Kanakaris, "Energy Efficiency in Underwater Sensor Networks: a Research Review,” Sci. Technol., vol. 3, pp. 151-156, 2010. Article (CrossRef Link)

[22] N.Z. Zenia, M. Aseeri, M.R. Ahmed, Z.I. Chowdhury, M. Shamim Kaiser, "Energy-efficiency and reliability in MAC and routing protocols for underwater wireless sensor network: A survey," J. Netw. Comput. Appl., vol. 71, pp. 72-85, 2016. Article (CrossRef Link)

[23] A. Darehshoorzadeh, A. Boukerche, "Underwater sensor networks: A new challenge for opportunistic routing protocols,” IEEE Commun. Mag., vol. 53, pp. 98-107, 2015. Article (CrossRef Link)

[24] R.W.L. Coutinho, A. Boukerche, L.F.M. Vieira, A.A.F. Loureiro, "Design guidelines for opportunistic routing in underwater networks,” IEEE Commun. Mag., vol. 54, pp. 40-48, 2016. Article (CrossRef Link)

[25] M. Ahmed, M. Salleh, M.I. Channa, M.F. Rohani, "Energy Efficient Routing Protocols for Underwater Wireless Sensor Networks: A Review,” TELKOMNIKA (Telecommunication Comput. Electron. Control., vol. 15, pp. 212, 2017. Article (CrossRef Link)

[26] T. Melodia, H. Kulhandjian, L. Kuo, E. Demirors, “Advances in Underwater Acoustic,” in: Mob. Ad Hoc Netw. Cut. Edge Dir. Second Ed., pp. 804-854, 2013.

[27] E. Felemban, F.K. Shaikh, U.M. Qureshi, A.A. Sheikh, S. Bin Qaisar, "Underwater Sensor Network Applications: A Comprehensive Survey,” Int. J. Distrib. Sens. Networks., 2015. Article (CrossRef Link)

[28] K. Chen, M. Ma, E. Cheng, F. Yuan, W. Su, “A Survey on MAC Protocols for Underwater Wireless Sensor Networks,” IEEE Commun. Surv. Tutorials., vol. 16,pp. 1433-1447, 2014. Article (CrossRef Link)

[29] A.T. Prodhan, R. Das, H. Kabir, G.C. Shoja, “TTL based routing in opportunistic networks,” J. Netw. Comput. Appl., Vol. 34, pp. 1660-1670, 2011. Article (CrossRef Link)

[30] C.J. Hsu, H.I. Liu, W.K.G. Seah, “Opportunistic routing - A review and the challenges ahead,” Comput. Networks., vol. 55, pp. 3592-3603, 2011. Article (CrossRef Link)

[31] S. Ghoreyshi, A. Shahrabi, T. Boutaleb, “A Novel Cooperative Opportunistic Routing Scheme for Underwater Sensor Networks,” Sensors., vol. 16, pp. 297, 2016. Article (CrossRef Link) 
[32] H. Shen, G. Bai, "Routing in wireless multimedia sensor networks: A survey and challenges ahead,” J. Netw. Comput. Appl., vol. 71, pp. 30-49, 2016. Article (CrossRef Link)

[33] Y. Noh, U. Lee, S. Lee, P. Wang, L.F.M. Vieira, J.H. Cui, M. Gerla, K. Kim, "HydroCast: Pressure routing for underwater sensor networks,” IEEE Trans. Veh. Technol., vol. 65, pp. 333347, 2016. Article (CrossRef Link)

[34] M. Tariq, M. ShafieAbd Latiff, M. Ayaz, Y. Coulibaly, N. Al-Areqi, "Distance based Reliable and Energy Efficient (DREE) Routing Protocol for Underwater Acoustic Sensor Networks,” J. Networks., vol. 10, pp. 311-321, 2015. Article (CrossRef Link)

[35] A. Wahid, S. Lee, D. Kim, "A reliable and energy-efficient routing protocol for underwater wireless sensor networks,” Int. J. Commun. Syst., vol. 27, pp. 2048-2062, 2014. Article (CrossRef Link)

[36] H. Yu, N. Yao, T. Wang, G. Li, Z. Gao, G. Tan, "WDFAD-DBR: Weighting depth and forwarding area division DBR routing protocol for UASNs,” Ad Hoc Networks., vol. 37, pp. 256-282, 2016. Article (CrossRef Link)

[37] P. Xie, J.-H. Cui, L. Lao, "VBF: Vector-Based Forwarding Protocol for Underwater Sensor Networks,” in Proc. of Lect. Notes Comput. Sci. (Including Subser. Lect. Notes Artif. Intell. Lect. Notes Bioinformatics), pp. 1216-1221, 2006.Article (CrossRef Link)

[38] H. Yan, Z.J. Shi, J.H. Cui,” DBR: Depth-based routing for underwater sensor networks,” Lect. Notes Comput. Sci. (Including Subser. Lect. Notes Artif. Intell. Lect. Notes Bioinformatics). 4982 LNCS, pp. 72-86, 2008. Article (CrossRef Link)

[39] N. Javaid, M.R. Jafri, Z.A. Khan, U. Qasim, T.A. Alghamdi, M. Ali, "iAMCTD: Improved Adaptive Mobility of Courier Nodes in Threshold-Optimized DBR Protocol for Underwater Wireless Sensor Networks,” Int. J. Distrib. Sens. Networks., pp. 1-12, 2014. Article (CrossRef Link)

[40] X. Wu, G. Chen, J. Chen, "Energy-efficient and topology-aware routing for underwater sensor networks,” in Proc. - Int. Conf. Comput. Commun. Networks, ICCCN. 2010. Article (CrossRef Link)

[41] C.-J. Huang, Y.-W. Wang, H.-H. Liao, C.-F. Lin, K.-W. Hu, T.-Y. Chang, “A power-efficient routing protocol for underwater wireless sensor networks,” Appl. Soft Comput., vol. 11, pp. 2348-2355, 2011. Article (CrossRef Link)

[42] R.W.L. Coutinho, A. Boukerche, L.F.M. Vieira, A.A.F. Loureiro, "GEDAR: Geographic and opportunistic routing protocol with Depth Adjustment for mobile underwater sensor networks," in Proc. of 2014 IEEE Int. Conf. Commun., IEEE, pp. 251-256, 2014. Article (CrossRef Link)

[43] A. Wahid, D. Kim, "An Energy Efficient Localization-Free Routing Protocol for Underwater Wireless Sensor Networks,” Int. J. Distrib. Sens. Networks., pp. 1-11, 2012. Article (CrossRef Link)

[44] A. Khasawneh, M.S.B.A. Latiff, O. Kaiwartya, H. Chizari, “A reliable energy-efficient pressurebased routing protocol for underwater wireless sensor network,” Wirel. Networks., pp. 1-15, 2017. Article (CrossRef Link)

[45] C.-M. Chao, C.-H. Jiang, W.-C. Li, "DRP: An energy-efficient routing protocol for underwater sensor networks,” Int. J. Commun. Syst., vol. 30, e3303, 2017. Article (CrossRef Link)

[46] R.W.L. Coutinho, A. Boukerche, L.F.M. Vieira, A.A.F. Loureiro, "EnOR: Energy balancing routing protocol for underwater sensor networks," in Proc. of 2017 IEEE Int. Conf. Commun., IEEE, pp. 1-6, 2017. Article (CrossRef Link)

[47] S. Ahmed, N. Javaid, F.A. Khan, M.Y. Durrani, A. Ali, A. Shaukat, M.M. Sandhu, Z.A. Khan, U. Qasim, "Co-UWSN: Cooperative energy-efficient protocol for underwater WSNs," Int. J. Distrib. Sens. Networks, 2015. Article (CrossRef Link)

[48] N. Nicolaou, A. See, P. Xie, J.-H. Cui, D. Maggiorini, "Improving the Robustness of LocationBased Routing for Underwater Sensor Networks,” Ocean. 2007 - Eur., IEEE, pp. 1-6, 2007. Article (CrossRef Link)

[49] H. Yu, N. Yao, J. Liu, “An adaptive routing protocol in underwater sparse acoustic sensor networks,” Ad Hoc Networks., vol. 34, pp. 121-143, 2015. Article (CrossRef Link) 
[50] M. Ashrafuddin, M.M. Islam, M. Mamun-Or-Rashid, "Energy Efficient Fitness Based Routing Protocol for Underwater Sensor Network,” I.J. Intell. Syst. Appl. Intell. Syst. Appl., vol. 5, pp. 61, 2013. Article (CrossRef Link)

[51] A. Wahid, S. Lee, D. Kim, "An energy-efficient routing protocol for UWSNs using physical distance and residual energy,” Ocean. 2011 IEEE - Spain., pp. 1-6, 2011. Article (CrossRef Link)

[52] N. Kanthimathi, Dejey, "Balanced and Multi-objective Optimized Opportunistic Routing for Underwater Sensor Networks,” Wirel. Pers. Commun., 2016. Article (CrossRef Link)

[53] Z. Ma, Q. Guan, F. Ji, H. Yu, F. Chen, "An Efficient and Low-Signaling Opportunistic Routing for Underwater Acoustic Sensor Networks," in Proc. of Lect. Notes Electr. Eng., pp. 22-29, 2017. Article (CrossRef Link)

[54] J.M. Jornet, M. Stojanovic, M. Zorzi, "Focused beam routing protocol for underwater acoustic networks," in Proc. Third ACM Int. Work. Wirel. Netw. Testbeds Exp. Eval. Charact. WuWNeT 08. pp. 75, 2008. Article (CrossRef Link)

[55] Z. Zhou, B. Yao, R. Xing, L. Shu, S. Bu, "E-CARP: An Energy Efficient Routing Protocol for UWSNs in the Internet of Underwater Things,” IEEE Sens. J., vol. 16, pp. 4072-4082, 2016. Article (CrossRef Link)

[56] A.P. Das, S.M. Thampi, "Simulation Tools for Underwater Sensor Networks: A Survey,” Netw. Protoc. Algorithms., vol. 8, pp. 41, 2017. Article (CrossRef Link)

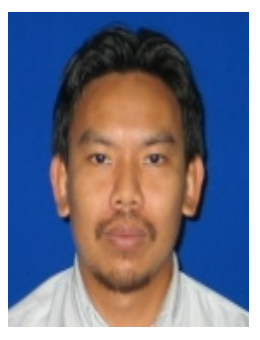

Nasarudin Ismail received the degree in Computer Science from the Universiti Teknologi Malaysia in 2001 and M.S. degree in Information Technology (Management) in 2011. He is currently staff at Universiti Tun Hussein Onn Malaysia and also a Ph.D. student at Universiti Teknologi Malaysia under supervision Dr. Mohd Murtadha Mohamad. His main research are on underwater sensor wireless networks.

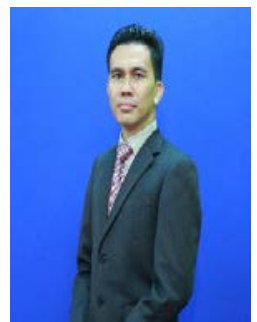

Mohd Murtadha Mohamad is a senior lecturer in Faculty of Computing, Universiti Teknologi Malaysia. He graduated with a degree of Bachelor in Engineering (Computer) from Universiti Teknologi Malaysia (UTM) in year 2000. He obtained his PhD in Electrical and Master of Science in Embedded System Engineering, from Heriot-Watt University UK. His current research interests are related to ad-hoc networks, underwater sensor wireless networks and indoor position. 